\title{
WITTGENSTEIN Y HEIDEGGER: LA PREGUNTA POR EL SENTIDO DEL SER Y LA SOSPECHA DE FALTA DE SENTIDO CONTRA TODA METAFISICA
}

\section{INTRODUCCIÓN}

La unión de los nombres de Wittgenstein y Heidegger en un ensayo filosó. fico suscita -a mi parecer con razón- todavía alguna extrañeza. Subrayo intencionalmente: la unión en un ensayo filosófico; pues en círculos literarios con sensibilidad para lo característico de la historia del espíritu esa misma unión ha adquirido desde hace mucho un excitante tono heurístico: como si en cierto modo fuera una llave para una comprensión más profunda de la estructura espiritual de nuestra época. En efecto: el historiador del espiritu no puede hoy ya pasar por alto que Wittgenstein y Heidegger representan figuras clave en la constelación filosófica de este siglo, por cierto, figuras clave para regiones de la filosofía moderna muy diversas, es más, recíprocamente cerradas con hermetismo. Y esta circunstancia a su vez justifica la extrañeza con respecto al intento de hallar una correlación sistemática, es más, quizá hasta un propósito común en el pensamiento de Wittgenstein y Heidegger.

La indicada oposición de sus mundos filosóficos se expresa tal vez en la circunstancia de que probablemente no sólo ambos pensadores representativos, sino también los representantes de sus escuelas en el más amplio sentido de la palabra, casi nunca han tomado nota seriamente unos de otros (aquí prescindo del intento de $\mathbf{R}$. Carnap de "hacer estallar en el aire con los medios de la lógica formal" ciertas tesis capitales de Heidegger. ${ }^{1}$ Efectivamente, es propio del carácter histórico de la más reciente filosofía que los conceptos titulares "filosofía existencial", "fenomenología", "ontologia fundamental", por una parte, "filosofía analítica", "positivismo lógico", "semántica" por otra, ponen de manifiesto no sólo contrastes de una orientación objetiva y metódica del pensamiento, sino también contrastes de mentalidad humana, por ejemplo, nacional. Se puede ilustrar el contraste espiritual de los conceptos titulares mencionados directamente en la geografía de la cultura: se puede distinguir claramente una zona de cuño anglo-sajón con irradiación hacia Escandinavia de una zona de cuño franco-alemán con irradiación hacia Sudeuropa y Latinoamérica.

1 Cfr. R. Carnap: "Uberwindung der Metaphysik durch logische Analyse der Sprache". En Erkenntnis, 2, 1932. [Trad. esp. de N. Molina Flores. en Cuadernos del Centro de Estudios Filosdficos, No 10, Imp. Univ., 1961.] 
¿Cómo sucedió que Wittgenstein y Heidegger, dos pensadores de lengua alemana, pudieran convertirse en exponentes de tan diversos mundos mentales?

Una característica exterior de esta constelación vista desde la perspec. tiva de los "prejuicios" tendría quizá el siguiente aspecto:

Heidegger filosofa como típico pensador alemán con la más alta exigencia especulativa, la cual se traduce aun en su lenguaje: él pretende repetir la tradición entera de la metafísica occidental, entendiéndola, y al mismo tiempo superarla. En ello la ciencia moderna y su nivel mental técnico metódico, por ejemplo su preciso lenguaje lógico-matemático, no sirven en modo alguno como medida de la superación espiritual, sino más bien como sintoma de aquello que, cual callejón sin salida en la historia del ser, ha de alejarse y superarse desde los orígenes: el desenvolvimiento de la metafísica en la técnica. Esta interna coyuntura del pensamiento heideggeriano, junto con la pretensión de su estilo frecuentemente apenas tolerable, parece tanto repugnar a los anglosajones y escandinavos, en el fondo creyentes en el progreso, como por otra parte favorece de modo manifiesto a un cierto resentimiento humanístico de las culturas latinas contra el predominio de la civilización técnica.

Por el otro lado, Wittgenstein, en cuanto discípulo de B. Russell, representa en cierta forma la mentalidad anglosajona. Considerando más de cerca el estilo críticamente, lo dicho se aplica sólo con restricción —pues también se puede documentar su parentesco espiritual con R. Musil, Karl Kraus, Kafka, y sobre todo con Lichtenberg-, y sin embargo acierta tan ampliamente que el Tractatus y las Investigaciones filosóficas pasan hoy por documentos clásicos de aquel filosofar fragmentario-analítico en torno a la ciencia experimental, que primero fue puesto en movimiento en América por Ch. $\mathrm{S}$. Peirce y luego en Inglaterra por B. Russell y G. E. Moore. Es fácil que al lector alemán ese pensamiento le parezca carente de algo substancial, lo que al menos está también condicionado porque, en espera de perspectivas positivas e ideológicas, apenas si será capaz de advertir al principio los sutiles puntos del análisis crítico-lingǘstico. Aquel espíritu no especulativo, o mejor "antiespeculativo", que domina a la filosofía inglesa desde Occam, Hobbes, Berkeley y Hume, y la hace tan poco atractiva para pensadores como Hegel, Schelling o Heidegger, aquella sospecha escéptica contra la metafísica por medio de la crítica del lenguaje, que caracteriza al nominalismo inglés - todo esto parece salir a la luz explícitamente en su negatividad justo en el Tractatus de Wittgenstein: como universal sospecha de falta de sentido contra todas las proposiciones ontológico-especulativas.

Ahora bien, precisamente este fundamental principio critico de sentido de la filosofía de Wittgenstein me parece hacer posible la comparación entre Wittgenstein y Heidegger. 
No sólo Wittgenstein, también Heidegger abriga frente a la metafísica tradicional qua ontología una sospecha crítica de sentido, que se manifiesta en la pregunta fundamental por el sentido de "ser": para el Wittgenstein maduro la metafísica se funda en una especie de "auto-enajenación" del lenguaje, cuya auténtica función (práctico-vital) es "malentendida" en el planteamiento filosófico del problema y cae en "olvido" en la "metafísica". Para Heidegger la "metafísica" se funda en el inicial auto-"malentendido" de la pregunta por el ser y en el "olvido" de éste resultante de ahí mas esto quiere decir, pensado desde el hombre: se funda en una especie de "autoenajenación" de la "ec-sistencia" humana, la cual "malentiende" su más peculiar empeño, el ser -que está siempre en juego en toda comprensión del mundo-, al abandonarse, en la expresión lingüístico-categorial de ese empeño, a la mirada del ente, con el que se tropieza dentro del mundo.

Al hacer el paralelo lingüístico del punto de partida de Wittgenstein y de Heidegger acabo de emplear intencionalmente el término "auto-enajenación". Con este motivo puede recordarse una tercera crítica a la metafísica tradicional, en boga al presente, que parte asimismo de una sospecha fundamental: a la "sospecha de falta de sentido" de Wittgenstein y a la sospecha del "olvido del ser" de Heidegger precedió la "sospecha de ideología" de Karl Marx dirigida contra la metafísica. Esta consideración lateral puede servir para delinear por completo el horizonte histórico-espiritual, dentro del que esferas de la filosofía contemporánea presentan, por más heterogéneas y reciprocamente separadas que parezcan, un punto de referencia común.

El punto de referencia común en conexión con nuestro problema es la puesta en cuestión de la metafísica occidental como ciencia teórica.

Así pues, en lo que sigue yo deseo comparar entre sí a Heidegger y a Wittgenstein desde el punto de vista de que a través de ambos, cada uno de diversa manera, la metafísica occidental es puesta en cuestión y con ello es desplazada por nosotros fácticamente como un fenómeno histórico. El punto de vista de nuestra comparación puede determinarse con más exactitud, si tenemos ante los ojos la pregunta fundamental de Heidegger sobre el sentido del ser y la pregunta fundamental de Wittgenstein sobre el sentido de proposiciones filosóficas como maneras de la crítica de sentido.

Una dificultad técnica para nuestro propósito parece resultar del hecho de que ambos pensadores por comparar, al menos en la conciencia de la opinión pública, pasaron por una transformación no insignificante. Se suele distinguir entre el Wittgenstein primero del Tractatus logico-philosophicus y el Wittgenstein posterior de las Investigaciones filosóficas, de manera semejante como se distingue entre el Heidegger antes y después del llamado "retorno" del "análisis de la existencia" a la "historia del ser". No obstante se mostrará que la suprema escala de comparación en que tenemos fija la mirada es apta para allanar ampliamente las dificultades del problema de periodi- 
zación. Precisamente el distanciamiento crítico de sentido de la metafísica tradicional es, en efecto, el punto de vista que, en forma de sospecha de falta de sentido, enlaza al Wittgenstein primero con el posterior, y que, por otra parte, también en Heidegger fija el concepto equivalente, invariable respecto del motivo de filosofía de la existencia, como del de historia del ser.

La primera y más importante cuestión que hemos de plantear a ambos pensadores - de acuerdo con las precedentes reflexiones-, tiene que ser la cuestión sobre el concepto de la metafísica teórica, de la cual se distanciaron ellos en cada caso. A continuación de esto habrá de preguntarse, cómo el concepto positivo del pensamiento crítico presupuesto en ambos filósofos se relaciona con el concepto de la metafísica criticada, y si o hasta dónde el concepto positivo de filosofía del uno coincide con el concepto críticamente rechazado del otro.

En esto procederemos técnicamente, poniendo primero en relación la “ontología fundamental” de Heidegger, con el Tractatus de Wittgenstein. En un segundo momento deben luego ser confrontadas las Investigaciones filosóficas del Wittgenstein posterior con la ontología existencial de Heidegger y con su destrucción de la "metafísica" (inclusive de la propia ontología).

\section{El "Tractatus logico-philosophicus" y la "ontología fundamental" de Heidegger}

El concepto de la metafísica, contra el que se dirige la crítica de sentido de Wittgenstein, constituye - por lo menos en el Tractatus- el presupuesto mismo de esta crítica de sentido. Se trata de la teoría de la figuración del mundo del "atomismo lógico", rastreable en los Principia mathematica de B. Russell hasta cierto punto como oculta metafísica de la logística, que Wittgenstein desarrolla ya en las dos primeras proposiciones fundamentales del Tractatus logico-philosophicus en forma original y pone como fundamento de toda consideración ulterior. Conforme a ello, el mundo es la suma de los "hechos", los cuales son figurados mediante los hechos-signos del lenguaje o proyectados en el "espacio lógico" como hechos posibles o "estados de cosas". Esta figuración o proyección de los hechos mundanos mediante hechos-signos del lenguaje es posibilitada por la "forma lógica" común para mundo y lenguaje.

Ahora bien, si la esencia de la representación lingüística del mundo consiste en la figuración de hechos mediante hechos en virtud de una forma idéntica, entonces la forma del mundo y del lenguaje no puede a su vez ser figurada, y esto significa: ser representada lingüísticamente; pues para ello la representación lingüística tendría que poder adoptar una posición fuera de su forma de representación, lo cual es imposible a priori. Por consiguiente, la forma a priori del mundo se anticipa a cada representación del mundo 
como condición de su posibilidad; "se muestra" cada vez sólo en la estructura lógica de la representación, como consta en Wittgenstein.

Esta conclusión, sorprendentemente simple, que Wittgenstein saca ya en la explicación de la segunda de las proposiciones fundamentales, 7 en total, del Tractatus, ${ }^{2}$ contiene ya el auténtico motivo fundamental de toda su filosofia ulterior: la sospecha de falta de sentido frente a todas las proposiciones metafisicas. Estas proposiciones, en efecto, no se contentan en verdad con hacer, en virtud de la forma a priori del lenguaje y del mundo, afirmaciones sobre hechos empíricos en el mundo, sino que elevan la pretensión de hacer a priori afirmaciones válidas sobre el mundo en su totalidad, es decir, empero, sobre la forma del mundo, es decir, a su vez, sobre la forma de la representación del mundo y con ello sobre su propia condición de posibilidad.

Como ejemplos de las proposiciones sin sentido de la metafísica aludidas por Wittgenstein, podemos en primer lugar -enteramente con su permiso- aducir las 7 tesis principales del Tractatus:

Las tesis 1: "El mundo es todo lo que es el caso" y 2: "Lo que es el caso, el hecho, es la existencia de estados de cosas", caen en la sospecha de falta de sentido, porque según su intención son afirmaciones sobre el mundo en su totalidad, es decir, sobre la forma a priori del mundo. Éstas no pueden de por sí concebirse como proposiciones de la ciencia positiva, como proposiciones sobre lo que es el caso, o -mediante la lógica de las funciones veritativas - reducirse a tales proposiciones. Y no satisfacen a este criterio de sentido establecido por Wittgenstein, precisamente en tanto que pretenden efectuar la fundamentación ontológica del criterio de sentido.

Junto con el fundamento ontológico del Tractatus, empero, son también víctimas de ese mismo criterio de sentido aquellas proposiciones relativas a proposiciones, en que el criterio de sentido es formulado inmediatamente, es decir, por tanto: las tesis 5 y 6 del Tractatus, en que -de manera exactamente análoga a las dos tesis ontológicas sobre la desintegración del mundo en "hechos" elementales- la analizabilidad básica del lenguaje es postulada en la forma de una reducción de toda proposición a "proposiciones elementales".

Es importante comprobar esto de inmediato; pues el positivismo lógico, como es sabido, intentó retener la parte analítico-lingüística del Tractatus y exhibir como metafísica sin sentido sólo la subestructura ontológica.

Sobre todo Carnap intentó poner de manifiesto inobjetablemente el sentido eventual de proposiciones ontológicas como "proposiciones pseudo-ob. jetivas" en la "manera formal de hablar" de la "sintaxis lógica". Consecuentemente, la proposición wittgensteiniana por ejemplo (I.1): "El mundo es la totalidad de los hechos, no de las cosas" debería poderse traducir en la proposición: "La ciencia es un sistema de proposiciones, no de nombres." s

2 Tractatus, proposición 2.172 y 2.174; además 4.12, 4.121.

3 Cfr. R. Carnap: The Logical Syntax of Language, Londres, 1937, pág. 3os. 
Debe aclararse que este intento de escapar al modo ontológico de hablar, está de acuerdo y coincide con la concepción de Carnap de la llamada manera formal de hablar, que como tal habla sólo de la forma externa, sensiblemente dada, de las proposiciones y de los nombres. Con todo, si se toma en serio esta concepción, entonces desaparece inmediatamente la justificación de la traducción carnapiana: a saber, la interna correspondencia de la proposición sobre el mundo y de la proposición sobre el lenguaje. Pues en su disposición externa, en cuanto producto de sonido o escritura, una "proposición" lingüistica no es ningún hecho, que pudiera reproducir un hecho extralingüístico. Una "proposición" concebida en el sentido de Carnap es exclusivamente una cosa, tal que según Wittgenstein puede resolverse en un hecho de la descripción mundana de las ciencias naturales. Sólo en virtud de la correspondencia semántico-categorial con una estructura ontológico-categorial de un hecho real se puede concebir la proposición lingüística según Wittgenstein como una figuración de la realidad.

Precisamente esto expresa Wittgenstein con claridad en las tesis 3 y 4 del Tractatus, las cuales sirven de enlace entre las tesis "ontológicas" (1 y 2 ) en sentido de Carnap y las tesis "lógico-sintácticas" (5 y 6) en sentido del mismo. : Ahí se dice:

Tesis 3: "La imagen lógica de los hechos es el pensamiento";

Tesis 4: "El pensamiento es la proposición con sentido".

Por tanto, si Carnap pretende entender a Wittgenstein mejor de lo que él mismo se entiende, al traducir sus proposiciones ontológicas en analíticolingüísticas, entonces la proposición wittgensteiniana: "El mundo es la totalidad de los hechos, no de las cosas", tiene que corresponder a la proposición: "La ciencia es la totalidad de las proposiciones verdaderas, no de los nombres."

Sin embargo, una proposición semejante es, según el criterio de sentido de Wittgenstein, tanto una proposición metafísica "sin sentido", como la proposición que estructuralmente le corresponde sobre el mundo como un todo. Es más, de acuerdo con Wittgenstein, sólo la traducción de la proposición ontológica en la analítico-lingüística produce de un modo explícito la "falta de sentido" de la primera. Pues, según Wittgenstein, precisamente esto es la razón de la "falta de sentido" de proposiciones sobre cosas en general, hechos en general, estados de cosas en general, en suma, sobre el mundo en su totalidad, de modo que pretendan hablar sobre la forma lógica común a lenguaje y mundo. Proposiciones ontológicas hablan de hecho implicitamente sobre la forma del lenguaje - esto lo concedería Wittgenstein a Carnap. Pero esto no salva su sentido, sino que antes hace plenamente inteligible, por qué proposiciones ontológicas tienen que ser absurdas:

4 Cfr. a este respecto Erik Stenius: Wittgenstein's Tractatus, a critical exposition of its main lines of thought. Oxford (Blackwell), 1960, págs. 182 ss. 
"La proposición puede representar la realidad total, pero no puede representar lo que ha de tener en común con la realidad, para poder representarla - la forma lógica.

Para poder representar la forma lógica, tendríamos que poder colocarnos con la proposición fuera de la lógica, es decir, fuera del mundo" (4.12).

Aún más estrechamente relacionado con el lenguaje formula Wittgenstein el mismo argumento crítico de sentido en la siguiente versión: "Ninguna proposición puede enunciar algo sobre sí misma, porque el signo proposicional no puede estar contenido en sí mismo." $\mathrm{Y}$ advierte aquí con referencia a B. Russell: "Esto es la entera theory of types" (3.332).

La referencia a la teoría de los tipos de Russell nos da ocasión para rechazar como irrelevante una ulterior interpretación ingenua de la paradójica autoanulación del Tractatus.

En la introducción a la edición inglesa del Tractatus, B. Russell mismo propuso resolver el problema del discurso lógicamente unívoco sobre la forma del lenguaje por medio de una "jerarquía de lenguajes artificiales" potencialmente infinita; ${ }^{5}$ y en círculos logísticos este consejo fue seguido celosamente y no rara vez recomendado como "la" salida del dilema wittgensteiniano. Frente a esto, sin embargo (como ya frente a Carnap), ha de subrayarse que en el Tractatus Wittgenstein puso a discusión no la forma sintáctica, que debe ante todo explicarse semánticamente, de un cálculo cualquiera, sino la forma del lenguaje real idéntica a la forma categorial del mundo conocible. Esta forma del lenguaje real, pues, existente en toda jerarquía de lenguajes artificiales, así sea ésta potencialmente infinita, se halla siempre presupuesta ya en la forma del lenguaje ordinario en cuanto último metalenguaje in actu. Esto "se muestra" - para hablar con Wittgenstein- en la circunstancia de que sólo con ayuda del lenguaje ordinario un cálculo de signos puede ser explicado semánticamente, lo cual significa, ser legitimado como lenguaje.

Es posible, por tanto, que la distinción de tipos-símbolo (Russell) o de tipos-lenguaje totales (Russell.Tarski) descarte con exito la reflexividad del lenguaje sobre sí mismo relativamente a la fundamentación de teorías científicas formalizables: mas respecto a la solución de la paradoja de la ontología expuesta por Wittgenstein y, al mismo tiempo, del análisis lingüístico ontológicamente relevante, todo depende de que justo la autorreflexividad del lenguaje $-y$ en tal sentido del conocimiento-, prohibida en la logística, sea posible.

Una semántica constructiva en el sentido de Tarski y Carnap es capaz, sin duda, mediante la exclusión de la autorreflexividad del lenguaje, de hacer imposible a priori la aparición de paradojas, como por ejemplo la paradoja

5 Cfr. Tractatus..., Londres, $7^{\mathrm{a}}$ ed., 195\&, pág. 29. 
del mentiroso, mas al mismo tiempo hace con ello también imposible el establecimiento de las llamadas "proposiciones totales", por ejemplo, de proposiciones sobre todas las proposiciones, y ello significa, sobre el lenguaje en general y su relación con el mundo. Pero eso quiere decir: la semántica constructiva significa el fin de la filosofía como ciencia teórica. Rudolf Carnap confirma esto en su artículo "Empirism, Semantics and Ontology" de $1950{ }^{6}$ al explicar el esbozo de un "framework" semántico ontológicamente relevante como un negocio de la "praxis". A esta consecuencia había llegado ya también. Wittgenstein en el Tractatus, donde se dice:

"...La filosofía no es una doctrina, sino una actividad. Una obra filosófica consiste esencialmente en explicaciones. El resultado de la filosofía no son 'proposiciones filosóficas', sino el aclaramiento de proposiciones..." (4.112).

Metafísica teórica, por tanto, según el Tractatus de Wittgenstein, es el arrogamiento, ilustrado en el Tractatus mismo con apodíctica pretensión, de un metalenguaje filosófico, es decir, empero, el intento de poner a discusión lo que en un discurso con sentido solamente se "muestra" como condición de posibilidad de ese discurso: la forma lógica del lenguaje y del mundo descriptible.

Con esta característica de la dimensión de la metafísica el Wittgenstein primero se coloca fácticamente en el horizonte problemático de la "filosofía trascendental". ¿Hasta qué punto?

La filosofía trascendental planteó en Kant por primera vez la pregunta por la posibilidad de la metafísica como reflexión sobre las condiciones de posibilidad de la experiencia y en ello formuló como "principio supremo" el postulado de la identidad de las condiciones de posibilidad de la experiencia y de las condiciones de posibilidad de los objetos de la experiencia. Precisamente este postulado lo traspuso Wittgenstein de una "crítica de la razón pura" a una "crítica del lenguaje puro", como comprueba con razón el finlandés Erik Stenius. ${ }^{7}$ El límite entre aquello que según Kant es accesible a la razón teórica y aquello que constituye la apariencia trascendental del uso "superabundante" de la razón, procura determinarlo Wittgenstein mediante la distinción lógico-lingüística entre sentido y sinsentido, entre aque. Ilo que se puede decir y aquello que solamente se muestra. Sólo con relación a una experiencia posible pueden darse "proposiciones con sentido" - así se podría, apoyándose en Kant, formular el criterio de sentido wittgensteiniano de la figuración de hechos posibles.

Si se entiende de esta manera el Tractatus como trascendental crítica de sentido, se observa por cierto de inmediato, que Wittgenstein pone en cuestión de un golpe no sólo la posibilidad de una "metafísica dogmática" en el

6 En R. Carnap: Meaning and Necessity, Chicago, $2^{a}$ ed., $195^{6 .}$

7 Cfr. loc. cit., cap. XI. 
sentido de Kant, sino también la posibilidad de una filosofía trascendental científica como teoría del conocimiento. Ambos tipos de pensamiento filosófico hablan según Wittgenstein en cierto modo sólo desde dos lados sobre lo mismo: sobre las condiciones de posibilidad del habla, que al mismo tiempo son condiciones de posibilidad de los objetos del habla. De estas condiciones trascendentales -de la estructura interna o "forma lógica" idéntica en lenguaje y mundo- empero, no se puede, según Wittgenstein, per definitionem "hablar". La forma trascendental "se muestra" sólo con ocasión de cada habla — se ha intentado completar con Heidegger: se muestra como la "previo-concomitante" comprensión del ser del habla actual sobre hechos ónticos.

Así llega Wittgenstein a declarar tanto la ontología dogmática como también la crítica lingüística a priori (trascendental), y con ello el contenido filosófico entero de su propio Tractatus, como metafísica sin sentido. A ella se aplica totalmente la $7^{\mathrm{a}}$ y última proposición fundamental del Tractatus: "De lo que no se puede hablar, sobre ello se tiene que callar."

( $Y$ se entiende de suyo que también esta proposición queda sujeta al mismo veredicto de falta de sentido, en tanto que tiene la pretensión de ser algo más que una mera tautología.)

Quizá se estará inclinado a considerar como absurda la paradójica problemática de falta de sentido del Tractatus vista desde el llamado sentido común humano. ¿No demuestra Wittgenstein precisamente por medio de las proposiciones de su Tractatus, que nosotros hombres estamos en condiciones de poner a discusión la relación entre lenguaje y mundo en su totalidad? $\mathbf{Y}$ ¿no sucede esto en proposiciones que según su estructura gramatical externa no son diferentes de proposiciones sobre hechos intramundanos? Así, por ejemplo, la proposición: "el mundo se descompone en hechos", se puede establecer según el mismo plano constructivo que la proposición: "el pastel se descompone en pedazos".

Sin embargo, precisamente esta semejanza externa de las proposiciones filosóficas y de las empíricamente verificables constituye el verdadero obstáculo para la sospecha de falta de sentido de Wittgenstein. Y con tal motivo se debería recordar que también las proposiciones de la crítica kantiana de la razón, precisamente por su fatal semejanza con las proposiciones sobre la experiencia posible, provocaron el escándalo de los filósofos de su tiempo. Cuando Kant habló sobre la "afección de nuestros sentidos" por medio de la "cosa-en-sí", sonó exactamente igual como si se hablara de una relación causaī en el mundo de la experiencia; y sin embargo, Kant habló aquí de aquello sobre lo cual la "categoría" de causalidad no debería encontrar ninguna aplicación. ¿Son entonces sin sentido las proposiciones filosófico-trascendentales de Kant sobre la cosa-en-sí? Jacobi pareció inclinarse casi a esta concepción. - $\mathrm{O}$ Łrepresenta la estructura gramático-sintáctica de las propo- 
siciones trascendental-filosóficas una metáfora? ¿Es una "traducción" de la estructura de proposiciones empíricamente verificables a relaciones de alguna manera análogas?

Tanto en Kant como también en Wittgenstein fue ensayada una interpretación semejante (más o menos en la línea de las doctrinas medievales sobre la significación impropia o análoga) ${ }^{8}$ El ya mencionado Erik Stenius, por ejemplo, entiende las proposiciones semántico-trascendentales y a la vez ontológicas de Wittgenstein sobre la forma del lenguaje y a la vez del mundo como "metáforas sintácticas". 9

Una metáfora sintáctica es, por ejemplo, la proposición "rojo no es una substancia (sino una cualidad)". En efecto, para impugnar la substancialidad de rojo, necesito ante todo ponerla, no obstante, en la forma-sujeto-predicado de la proposición "rojo es...". Del mismo modo sucede en todas las "afirmaciones" sobre categorías. Que, por ejemplo, una substancia no es una cualidad, no se puede "propiamente" afirmar según Wittgenstein, sólo "se muestra" en el uso del lenguaje. Si pretendo afirmarla directamente, entonces la afirmación toma en su forma la apariencia de una proposición sobre hechos empíricos.

Todavía más básicas para la fundamentación de la ontología en general son proposiciones de la forma:

"x es un ente".

Debido a su estructura sintáctica tendrían que ser entendidas como proposiciones de la forma: " $x$ es un caballo". Pero en realidad no tratan en manera alguna de un concepto genérico, que determine la clase de los valores posibles de las variables, sino que, según Wittgenstein, explican en cierto modo tautológicamente el sentido de las variables en la función proposicional "x es...", pero de manera que surge la impresión de que se da un género universal "ente", así como se dan plantas, animales y hombres.

Ya Aristótelès había tratado de prevenir este malentendido con la ob-

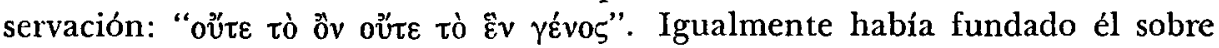
el concepto del ôv mada después "metafísica", como ciencia teórica.

Para Wittgenstein el hablar del ente y sus categorías es en cierto modo el pecado original de la autoenajenación de la función lingüística, que condujo al nacimiento de la metafísica como una ciencia aparente pseudo-objetiva. Proposiciones de la forma "x es un ente" son para él "sin sentido", porque deben reproducir la estructura lógico-lingüistica de las variables, en la que se "muestra" la función designativa del lenguaje, justamente por

8 Cfr. por ejemplo E. K. Specht: "Der Analogiebegriff bei Kant und Hegel." Colonia, $1952=$ Kantstudien, Erg. Hefte, Bd. 66 .

${ }_{9}$ Cfr. Stenius, loc. cit., págs. 211 ss. 
medio de esta función designativa. El mismo malentendido originario de la lógica de nuestro lenguaje se atestigua según Wittgenstein en proposiciones aparentes, como: "eso es un objeto" o "eso es un hecho", o: "se dan estados de cosas", o bien: "se dan más de 3 estados de cosas".10 Sin embargo, Wittgenstein no puede menos de suponer la implícita ontología de la forma lógica del lenguaje, por ejemplo de la estructura de las variables $(x)$, y explicarla en su propio metalenguaje. El sentido ontológico de " $x$ es" no puede en ningún caso, como veíamos, ser sustituido mediante convenciones sintácticas al estilo del Carnap primero; más bien sólo ese sentido asegura la función semántica del lenguaje. Así, para Wittgenstein no cabe duda alguna de que, por ejemplo, el desempeño de la variable $x$ en " $x$ es inteligente", muestra en forma implícita, mediante el nombre propio Hans, que Hans "existe". Mas si yo enuncio la proposición "Hans existe" como ilustración de una ciencia ontológica, ya estoy dentro del "sinsentido"; pues la proposición suena como ésta: "Hans canta". ¿Cómo puede la filosofía escapar a esta "apariencia metafórica" de su lenguaje? - ¡Êste es el verdadero problema que Wittgenstein planteó en el Tractatus!

Tratemos de establecer en este punto una relación entre Wittgenstein y Heidegger.

También para Heidegger se oculta en las proposiciones citadas de la ontología como ciencia del ente en cuanto tal por lo menos una profunda ambigüedad, que - para hacer visible el paralelo con la crítica de sentido de Wittgenstein - se puede interpretar como un auto-malentendido histórico de la pregunta por el "ser", conductora de la ontología: la proposición, por ejemplo: "eso es un ente", sugiere para Heidegger una confusión de aquello que se muestra en el "es", con lo que se muestra en el "eso". Esto último se revela como el aspecto "óntico" de la ontología en proposiciones empíricas. como "eso es un caballo". Por el contrario, lo que se "muestra" a la mirada del filósofo en el "es" de la proposición, según Heídegger, es la comprensión del ser que aparece de manera "previo-concomitante" en todas las proposiciones del hombre sobre caballos, árboles, casas, etc. Y esta "preontológica" comprensión del ser implícita en el lenguaje determina también para Heidegger - no de otra manera que para Wittgenstein - las condiciones de posibilidad de la experiencia, llamadas por Kant transcendentales, que son idénticas a las condiciones de posibilidad de los objetos de la experiencia. Por tanto, si ya en lo anterior habíamos podido interpretar la distinción wittgensteiniana entre lo quc se puede decir y lo que solamente se muestra, como expresión de la "diferencia transcendental" de Kant, ahora se muestra esta diferencia como expresión de la "diferencia óntico-ontológica" de Heidegger.

10 Cfr. Tractatus, $4 \cdot 1272$. 
Desde la perspectiva de Heidegger se podría, por tanto, intentar una respuesta positiva a la sospecha de falta de sentido, fundamental para Wittgenstein, más o menos en la siguiente forma: Lo que en todo discurso aparece de modo "previo-concomitante", lo que según Wittgenstein sólo se "muestra", pero no puede ser dicho, es el "ser". El ser, empero, no "es". Sólo un determinado ente que se halla en el mundo "es". Por eso el ser no puede tampoco decirse en proposiciones verificables empíricamente. Sólo un "ente" que se encuentra dentro del mundo puede ser objeto de proposiciones verificables empíricamente. El "ser", por el contrario, "se temporaliza" en el "proyecto mundano", el cual nos hace entrega siempre (a priori) de todo ente, que debe podernos encontrar dentro del mundo, en la forma categorial de lo que es afirmado de él en el decir-"es". En este proyecto mundano nosotros hombres nos anticipamos siempre, en cuanto que en la forma del lenguaje se consolidó ya una precomprensión de la concepción del ser del ente. Si elevamos a concepto esta previa comprensión del ser, entonces no se trata de la comprobación teórica de algo que junto a otra cosa además se dé, sino de la post-ejecución mental de la "preontológica comprensión del ser" del lenguaje.

Se entiende desde aquí que para Heidegger la filosofía no es, en último término, exactamente tan poco como para Wittgenstein, una teoría científica junto a otras teorías científicas. No es un sistema de proposiciones que pudiera entrar en concurrencia con proposiciones científicas. Si Wittgenstein resuelve la paradójica problemática del sentido de proposiciones filosóficas pör sí mismas prácticas, concibiendo la filosofía no como una ciencia, sino como "actividad" de la aclaración de pensamientos, entonces se puede com. probar en Heidegger una tendencia muy semejante en la autocomprensión de su filosofar.

Ya en El ser y el tiempo y en el libro sobre Kant acentúa Heidegger el carácter de proyecto, que a veces incluye violencia, de un pensamiento que pretende no establecer algo sobre lo existente dentro del mundo, sino sacar a la luz, hacer "manifestar-se" los previo-concomitantes fenómenos de la comprensión del ser. ${ }^{11}$ Más tarde identifica él -n crasa oposición a la metafísica como ciencia teórica - el pensamiento del ser con la "ejecución de la verdad del ser", acentuando por cierto que precisamente esta ejecución no va a terminar en un hacer arbitrario y en actividad negocial, sino en un atento acoplarse a la exhortación del ser que se acerca. ${ }^{12}$

Con este motivo puede recordarse que la semántica constructiva procedente del Tractatus de Wittgenstein, como la del Carnap posterior, caracte-

11 Cfr. Sein und Zeit, § 7 [Trad. esp. de José Gaos, F. C. E., México, $1^{\natural}$ ed., 1951, $2^{\mathrm{a}}$ ed. 1962]; Kant und das Problem der Metaphysik, $\S$ 12. [Trad. esp. de G. Ibscher Roth y E. C. Frost, F. C. E., México, 1953.]

12 Cfr. Uber den Humanismus, Frankfort, 1949. 
riza expresamente el problema de la implícita ontología del lenguaje, dicho de otra manera: el problema del proyecto mundano inmanente al lenguaje, como un problema de la praxis. ${ }^{13}$ En ello la aparente arbitrariedad de la construcción semántica es -si se quiere- proporcionada en la "historia del ser" por el hecho de que un sistema lingüístico artificial sólo puede entrar en función, si puede ser interpretado con ayuda del lenguaje tradicional de la ciencia - como su precisamiento fragmentario. En otras palabras, el "proyecto mundano" del lenguaje artificial tiene que legitimarse ex professo como posible continuación del lenguaje histórico o de su inmanente constitución mundana. ${ }^{14}$

En cualquier caso, lo que se puede comprobar según las disquisiciones anteriores es esto: tanto en la concepción wittgensteiniana de la filosofía como "actividad de aclaración del pensar" o en su ejecución como semántica constructiva, como por otro lado en la proyectiva radicalización heideggeriana de la comprensión preontológica del ser del lenguaje, la comprensión tradicional-metafísica de la filosofía como una ciencia teórica fundamental queda por principio superada. Y si miramos las cosas con exactitud, entonces la praxis de la semántica moderna, su mediación circular entre construcción del lenguaje y legitimación subsiguiente con ayuda del lenguaje ordinario, se presenta como un caso especial de lo que Heidegger evidenció como el "círculo hermenéutico" entre el "estado de yecto" y el "proyecto" de la comprensión del ser en El ser y el tiempo.

Sin duda, todo esto que acabamos de comprobar sobre la diferencia ontologica, según Wittgenstein no puede decirse en general, a menos que se quiera llegar de nuevo a la corriente de una metafísica cuasi-teórica. Heidegger, por otra parte, acometió de lleno - por lo menos en El ser y el tiem. po- la empresa de enunciar en una forma universalmente obligatoria la estructura del "dejar el ser del ente" a priori conforme al proyecto mundano de la existencia. Él llamó este intento "ontología fundamental". Después de todo lo previamente dicho resulta ahora la tarea o de desenmascarar la ontología fundamental de Heidegger desde la perspectiva de Wittgenstein como una recaída en la metafísica teórica, o de mostrar que la ontología fundamental de Heidegger es capaz de resolver el problema básico de Wittgenstein de un discurso filosófico con sentido acerca de la forma a priori del discurso y su relación con la forma de la realidad.

En este punto, pues, es preciso atender a la circunstancia de que la crítica wittgensteiniana, lógicamente orientada, del lenguaje puro en el Tractatus,

13 Cfr. supra pág. 118, nota 6. La distinción hecha en otro lugar por Carnap entre "internal question" y "external question" no es una mala ilustración para la "diferencia ontológica" de Heidegger.

14 Cfr. a este respecto K. O. Apel: Die Idee der Sprache in der Tradition des Humanis. mus von Dante bis Vico, Bonn, 1963, págs. 23 ss. 
es decir, su teoría de la forma idéntica del lenguaje y del mundo, sólo representa un caso límite de lo que según Heidegger se podría llamar la "preontológica comprensión del ser" del lenguaje.

Visto desde la posición de la filosofía trascendental tradicional, lo extraño del Tractatus se halla en que identifica las condiciones formales de posibilidad de toda experiencia con la forma lógica en sentido tautológicoanalítico. La "lógica formal" debe, por tanto, como parece, lograr también aquello que es en Kant la tarea de una "lógica trascendental". Que, por ejemplo, el mundo se descomponga en circunstancias en cuanto enlaces de cosas o substancias, caracteriza según Wittgenstein las propiedades "internas" o a priori del mundo, que son idénticas a las propiedades "internas" o "formales" del lenguaje.15 También la estructura geométrica del espacio y la llamada "ley de causalidad" pertenecen a estas propiedades "internas" del mundo, que son condicionadas por la "forma lógica" del lenguaje.16 Por qué la estructura interna del lenguaje y del mundo está así constituida — sobre esto no se da ninguna información, es más, ya el que proceda así no es, según Wittgenstein, "propiamente" expresable: ello se "muestra" como lo trascendental de la lógica formal misma. ${ }^{17}$

Con esto guarda muy estrecha relación el que, según Wittgenstein, no se pueda dar "propiamente" ninguna filosofía del sujeto.18

En efecto: para una filosofía trascendental, que sustituye la constitución sintética de la objetividad frente a una conciencia por el factum trascendental de la lógica del lenguaje, para una filosofía semejante la "conciencia en general" o el sujeto trascendental coincide absolutamente con la forma $a$ priori del lenguaje. $Y$ así puede Wittgenstein decir:

"Que el mundo es mi mundo, esto se muestra en que los límites del lenguaje (del único lenguaje que yo entiendo) significan los límites de mi mundo." (5.62)

Y Wittgenstein concluye de ahí:

“..., que el solipsismo, sostenido rigurosamente, coincide con el realismo puro. El yo del solipsismo se contrae a un punto inextenso, y sólo queda la realidad a él coordinada". $(5.614)^{18}$

Aquí se muestra en forma extrema el carácter de caso límite de la filosofía trascendental wittgensteiniana del lenguaje. En tanto el sujeto es absolutamente idéntico al proyecto mundano formal del lenguaje puro trascendental, cesa toda reflexividad, toda reflexión del sujeto sobre su proyecto mundano de lenguaje. Todo se conduce en tal forma, como si no existiera

15 Cfr. Tractatus, 2.0121-2.0131.

16 Cfr. Tractatus, 2.0131, 6.32, 6.33, 6.36, 6.361.

17 Cfr. Tractatus, 6.1g: "La lógica no es una doctrina, sino una imagen reflejada del mundo. La lógica es 'trascendental'".

18 Cfr. Tractatus, 5.691, 5.633 .

19 Cfr. $5.632,5.641$. 
absolutạmente sujeto alguno. Sólo se dan los hechos reales así como son ya figurados siempre para nosotros por el lenguaje.

Ahora bien, con ello hemos descubierto la verdadera razón de por qué para la filosofía trascendental del Wittgenstein primero no puede darse ningún discurso con sentido del lenguaje sobre sí mismo y su relación con el mundo, y esto quiere decir, no puede darse ningún lenguaje con sentido de la filosofía trascendental: en el Wittgenstein del Tractatus, que orientaba su comprensión lingüística hacia el lenguaje calculatorio de la logística, el lenguaje, y con ello el sujeto en la representación del mundo, se anticipa en cierto modo integramente - para hablar con el Heidegger primero. El lenguaje reproduce sólo estados de cosas existentes, pero no ofrece en la representación del mundo al mismo tiempo también la relación del hombre consigo mismo, es decir, con sus posibilidades de existencia, ni, de ese modo, la indole de su proyecto del mundo.

Esta radicalización de la "diferencia trascendental" entre lenguaje y metalenguaje es al menos sugerida por la "lógica del lenguaje", que desde antiguo aísla "juicios" particulares sobre los llamados "estados de cosas" -o en todo caso conclusiones de unos estados de cosas a otros estados de cosas-, como muestra de la función lingüística. Pues en proposiciones afirmativas aisladas sobre estados de cosas no parece demostrable ninguna autorreflexividad del lenguaje. Sin embargo, no ocurre enteramente asi: hasta en la proposición afirmativa aislada se da un elemento que no puede concebirse desde la teoría figurativa de Wittgenstein, y que más bien expresa implícitamente una autorrelación del lenguaje: toda proposición afirmativa afirma su propia verdad mediante el "es" de la cópula, que puede también estar implícito en la forma conjugada del verbo.

Esta afirmación, que de acuerdo con el Tractatus asevera que un "estado de cosas" existe como "hecho",20 no es tampoco entendida por Wittgenstein desde la función figurativa. Por ejemplo, en la proposición: "el libro está sobre la mesa", la unión representativa mediante "combinación de los nombres" afecta sólo al estado de cosas: "el libro... sobre la mesa". El "es", por el contrario, que asevera la existencia del estado de cosas, tiene que ser entendido puramente como expresión de la forma lógica del lenguaje.

Ahora bien, puesto que, como señalamos en lo anterior, la forma lógica del lenguaje según Wittgenstein coincide de modo estrictamente tautológicoanalítico consigo misma y a la vez con el "yo" del sujeto trascendental, por eso el "es" en cuanto partícula lógica no puede representar para Wittgenstein ni una síntesis a priori de la conciencia de objetos ni una síntesis como la de la autoconciencia. El sentido del “es" se reduce al tautológico $A=A$ de

20. Cfr. 4.002: "La proposición muestra su sentido. La proposición muestra cómo se conduce cuando es verdadera. Y ella dice que se conduce así." Cfr. también 4.062. 
la matemática, y con ello toda autorreflexividad del lenguaje, a la vez que toda autorrelación del sujeto trascendental, queda descartada de antemano.

A mi parecer, la importancia de esta posición como caso límite de la filosofía trascendental se puede aclarar tal vez con la siguiente ficción: supongamos que ocurriera en realidad de tal modo que la forma interna de nuestro lenguaje fuera, por una parte, un a priori absoluto ordenador del mundo y, por otra parte, tautológicamente idéntico consigo mismo: entonces nosotros hombres tendríamos sin duda una comprensión del mundo con garantía de validez universal. Esto quiere decir, empero, que concebiríamos los estados de cosas absolutamente relevantes para la vida más o menos así como lo hacen las bestias conforme a la teoría uexkülliana del mundo circundante, ${ }^{21}$ es decir, sin ninguna conciencia concomitante de una relación vital con el mundo, relación que constituye la importancia de los estados de cosas, y en esa forma sin la posibilidad de una reflexión sobre el proyecto mundano perteneciente a esa relación vital. De hecho, según el Tractatus de Wittgenstein, el hombre es tan poco capáz de dar cuenta de la constitución del mundo lingüístico de significado, como el animal acerca de la constitución "de su mundo de operación y percepción", que está subordinado a priori a su conducta instintiva.

Ahora bien, no se puede enteramente negar que desde el punto de vista de la lógica la interpretación del contenido del mundo "en cuanto algo" es siempre supuesta ya como acabada. Por eso, la filosofía del lenguaje de los antiguos y aun de la Edad Media, que nació en el ámbito, es más, hasta cierto punto como apéndice semiótico de la lógica, jamás advirtió algo de las diversas interpretaciones anteriores del mundo propias de las lenguas populares individuales. En lo que se refiere a la lógica, parece como si el estado de cosas, por ejemplo: "el libro (está) sobre la mesa", estuviera dado como perfecto en forma del todo independiente del "es" de la cópula y con ello del estar-en-el-mundo del hombre. El "es", como ya se indicó, parece expresar una relación con el hombre, en todo caso como reconocimiento del estado de cosas qua hecho, que existe independientemente del hombre.

Pues bien, la absoluteidad del hecho, que se comprueba en la proposición: "el libro está sobre la mesa", no puede en manera alguna impugnarse. Pero existe como algo puramente por reconocerse aún - sólo bajo el supuesto "de que esto sea un libro", o "que esto sea una mesa", es más, aun bajo el supuesto de que un libro pueda estar "sobre" una mesa. Ahora bien, la constitución de estos supuestos no es, a ojos vistas, en manera alguna independiente del estar-en-el-mundo del hombre, para el cual pueden encontrarse cosas "como algo" o en determinados nexos circunstanciales. Pero esto quiere decir: la constitución de los supuestos mencionados no es solamente relativa a la exis-

21 Cfr. J. v. Uexküll: Umwelt und Innenwelt der Tiere, Berlín, 1909; $2^{\text {a }}$ ed., 192 1. Idem: Theoretische Biologie, Berlín, 1920; $2^{\text {a }}$ ed., 1928. 
tencia humana del modo como un "mundo de operación y percepción" es según Uexküll relativo a la existencia genérica animal, sino que más bien ha sido elaborada por el hombre en cierta forma junto con la construcción de su mismo lenguaje, por más que le sea a él poco consciente.

Si se sacan de estas reflexiones las consecuencias analítico-lingüísticas, resulta que no solamente el "es", qua reconocimiento de un estado de cosas como hecho existente, expresa una relación del hombre con el mundo, sino también ya el "es" como cópula del llamado "estado de cosas". Muy lejos de ser inesencial para el estado de cosas mismo, el "es" de la cópula pone de manifiesto más bien la circunstancia de que ya los miembros del esiado de cosas, supuestamente sólo por designarse, deben su constitución "en cuanto algo" a una sintesis, que corresponde a una relación de ser del hombre consigo mismo. Ni un animal ni un espíritu puro, sino sólo el hombre, que posee una relación inteligente hacia su ser en cuanto posibilidad, es capaz de "dejar-ser" algo como "libro" o "mesa", mas esto quiere decir, ganar para el mundo una significación.

Esta correspondencia fundamental de la síntesis hermenéutica de "algo en cuanto algo" con la autocomprensión del hombre tiene que dar el sello al proyecto mundano total del "lenguaje-ordinario". En oposición al ideal logístico de un lenguaje simbólico figurador de estados de cosas existentes, el lenguaje real tiene que representar siempre en la concepción del mundo juntamente una relación del hombre consigo mismo, de otro modo no tendría él absolutamente nada que pudiera representar "como algo". En esta prerreflexiva autorrelación del discurso humano -así se podría pensar- tiene que hallarse la posibilidad de una superación de la paradoja fundamental del Tratado.

Se habrá observado que la crítica arriba intentada de los supuestos filosófico-lingüísticos del Tractatus se llevó a cabo desde el enfoque de la ontología fundamental heideggeriana; mas esto quiere decir, desde el enfoque de una filosofía trascendental, que precisamente en oposición a la del Wittgenstein primero no conduce la síntesis kantiana de la conciencia objetiva hacia el caso límite analítico del $\mathrm{A}=\mathrm{A}$, sino que, recayendo en la constitución preteórica del mundo vital, trata de fundarla, mediante la síntesis hermenéutico-trascendental del "algo en cuanto algo", en el nexo circunstancial de la praxis vital.

La entrega lingüística del ente, que se encuentra dentro del mundo "como algo" (es decir, en una "circunstancia"), corresponde aquí a la rèlación del hombre -más exactamente, de los miembros de una comunidad de lenguajecon las posibilidades de su poder-estar-en-el-mundo. Mediante esa inexpresable autorrelación de una comunidad de lenguaje está siempre proporcionada ya en su constitución la lingüística "visión del mundo", llamada así por Humboldt. (Se puede revisar esto fácilmente en un ejemplo, si con P. Zinsli 
se aclara el diverso descubrimiento del mundo alpino en el léxico de los dialectos campesinos, por una parte, y por otra, del alpinismo turístico. ${ }^{22}$ Con todo, se plantea la cuestión de si este entenderse-en-la-situación de los hombres, implicado constantemente en el lenguaje ordinario, de si esta "reflexión efectiva" del lenguaje histórico, como dice J. Lohmann, ${ }^{23}$ es una suficiente aclaración de la posibilidad de una reflexión filosófica sobre la forma interna del lenguaje, sobre la comprensión del ser ahí contenida.

Heidegger mismo ha hecho en El ser y el tiempo una clara distinción en. tre la autocomprensión "existencial" * en la situación, que corresponde a la "reflexión efectiva" del lenguaje, en el que "uno" se entiende, y la comprensión "existenciaria" de la filosofía. Según Heidegger, ésta tiene que "radicalizar" la "preontológica comprensión del ser", que está implícita en el existencial comprender-ser-relativamente a, para ponerlo en concepto. Mas, ¿cómo debe entenderse este "radicalizar"? ¡De la inteligencia de este término parece depender, en todo caso en El ser y el tiempo, la contestación de la pregunta por la posibilidad y validez de afirmaciones filosóficas!

Th. Litt acometió este problema en su libro Hombre y Mundo (Munich, 1948) y señaló que en su ontología fundamental, por ejemplo en la "indicación formal" de los llamados "existenciarios", Heidegger reivindica para el pensamiento un grado de reflexión, que es fundamentalmente diverso de la comprensión del ser inmanente a la existencia y a la historia, comprensión que trata de radicalizarlo, en forma que de este pensamiento -que concibe la "existenciariedad", por ejemplo, la "finitud" e "historicidad" de la comprensión humana del ser - ya no se puede decir simplemente que esté él mismo sólo existencialmente condicionado, y esto quiere decir: que sea finito e histórico. Litt mostró que la autorreflexividad dispuesta en todo lenguaje natural permite una explícita “autogradación del lenguaje”, que en último término hace valer la exigencia intersubjetiva de validez universal del logos filosófico en cada lenguaje individual. Esta exigencia de validez universal del lenguaje filosófico se constituye sobre un grado de reflexión superior al del "logos hermenéutico", que Heidegger reivindicó en $\mathrm{El}$ ser y el tiempo para la fundamentación de su filosofía. El logos hermenéutico del entender-seen-la-situación es, sin duda, suficientemente autorreflexivo para hacer posible, junto con la autocomprensión, a la vez la comprensión de la existencia ajena, por ejemplo, junto con la comprensión del lenguaje propio, a la vez la traducción desde un lenguaje extraño al propio; mas en ello hace valer él irremisiblemente la perspectiva individual-histórica del propio lenguaje o del

22 Cfr. P. Zinsli: Grund und Grat. Der Formaufbau der Bergwelt in den Sprachbegriffen der schweizerdeutschen Alpenmundarten, Berna, 1946.

23 Cfr. J. Lohmann: Philosophie und Sprachwissenschaft, Berlín, 1965 , Register.

- [La traducción española de la terminología heideggeriana -con pocas y ligeras variantes- es la establecida por el Dr. José Gaos en su traducción de esta obra editada por el F.C.E. Cfr. nota 11.] 
propio punto de vista existencial. El logos filosófico, por el contrario, que en el reiterado retorno al logos hermenéutico hace posible la "indicación formal" de tales conceptos como "individualidad", "historicidad", etc., "trasciende" al "logos hermenéutico" tan fundamentalmente como el último "trasciende" al logos teórico-objetivo del "lenguaje de objetos" (como la ciencia natural).

En el lenguaje ordinario vivo, por tanto, está dispuesta en cierta forma según Litt una inmanente "teoría de tipos" semántica, que preseñala a la autorreflexión humana los grados de sentido y universalidad posibles en general. Antes de la teoría logística de los tipos de B. Russell se la caracterizó mediante el hecho de que no condiciona ningún regressus ad infinitum, sino que mediante la elevación, ligada a la reflexión, de los grados de universalidad de las afirmaciones llega a un remate, que coincide con su autofundamentación, es decir, con la autorreflexión noológica de la filosofía. En el lenguaje del Wittgenstein joven esto significaría: el discurso filosófico sobre la forma lógica del lenguaje y a la vez del mundo no presupone en absoluto una posición fuera de lenguaje y mundo, sino que únicamente sigue a la reflexividad dialéctica de la forma lógico-trascendental del lenguaje. Aquí no va en juego una ontología de estilo prekantiano, que presente la relación del conocimiento o del lenguaje con el mundo como un "commercium entre un sujeto ante los ojos y un objeto ante los ojos" (Heidegger), en cierta forma desde un lado, sino una filosofía trascendental dialéctica y crítica de sentido. Ésta descubre la apariencia metafórica de la forma lingüística externa de proposiciones filosóficas y formula, por ejemplo, sus proposiciones sobre la relación entre lenguaje y mundo, de tal manera que se excluye una confusión de su sentido con el sentido de proposiciones lingüístico-objetivas mediante la regla del uso lingüístico que se halla en la autogradación dialéctica del lenguaje. ${ }^{24}$

Yo creo efectivamente que esta interpretación dialéctica, inspirada por Hegel, del metalenguaje filosófico contiene la única respuesta posible a la paradoja del Tractatus y con ello a la provocación de la sospecha wittgensteiniana de falta de sentido contra toda filosofía teórica. Sin embargo, queda por notar que esta solución de la pregunta por el sentido y posibilidad de la filosofía hace a ésta a la vez volver a la pobreza de su autosatisfacción sistemática; pues el lenguaje filosófico debe todo contenido de sentido, y aun el contenido material mismo de las categorías y existenciarios, al "logos hermenéutico", en el que el histórico estar-en-el-mundo articula su respectiva comprensión del ser. Para nosotros hombres, que al menos también somos finitos y estamos entregados a un futuro incierto, es imposible por principio

24 En esta forma hace uso de la teoría de la significación y del criterio de sentido del lenguaje, que el Wittgenstein posterior pone en juego contra la teoría de la figuración del Tractatus. 
identificar la substancial comprensión del mundo del engagement histórico, como quería Hegel, con la dialéctica sistemática de la reflexión y "suprimirla" en cuanto al contenido en el "saber del saber".

Esta reflexión hace aparecer comprensible, como me parece -aunque de ningún modo lo justifica-, que Heidegger no siguiera el camino, tal vez aún posible en El ser y el tiempo, de una renovación crítica de sentido ni de ensanchamiento de la filosofía trascendental, sino más bien creyera tener que distanciarse, dentro de la historia del ser, de la sistemática cuasi-teórica de su ontologia fundamental, aun hasta como expresión de la metafísica por superar de lo ante los ojos, a saber, de lo ante los ojos de una substancia óntica como sujeto de la conciencia.

Mediante esta decisión, que Heidegger mismo quisiera entender como necesario "retorno" de su pensamiento, dio en cierto sentido razón a la sospecha wittgensteiniana contra la metafísica teórica. Por ejemplo, él tomó a la letra la apariencia metafórica del hablar sobre el sujeto del pensamiento y de sus realizaciones activas -exactamente como Wittgenstein-y lo interpretó como abandono a la mirada de lo que se encuentra dentro del mundo y está presente de continuo. Esta tendencia al desenmascaramiento del lenguaje de la metafísica, orientado hacia la lógica de la objetividad, lleva nuevamente a Heidegger lo más cerca posible de la crítica del lenguaje de Wittgenstein, como éste la desarrolló en su obra posterior, las Investigaciones filosóficas. Tanto Heidegger como Wittgenstein creen en último término deber evitar a todo precio las sugestiones representativas de toda onto-lógica tradicional, a fin de hacer que se muestre lo encubierto y olvidado en esas rígidas esquematizaciones e idealizaciones: el "ser" que acontece en el "juego-espejo" de la iluminación mundana (Heidegger) - o el "juego lingüistico" malentendido en toda metafísica (Wittgenstein).

\section{Las "INVESTigaciones filosóficas de Wittgenstein" y la "Destrucción" DE LA "METAFísica" DE HeidegGer}

En el Tractatus logico-philosophicus Wittgenstein condenó la metafísica teórica como "sin sentido", sólo en cuanto que con los medios semántico-sintácticos de un lenguaje, que sólo puede figurar "estados de cosas" existentes dentro del mundo, pretende poner a discusión las condiciones ontológicas y trascendentales de posibilidad de la figuración de estados de cosas. Mas esto quiere decir: en esa obra de juventud Wittgenstein no puso en cuestión, respecto al contenido, la ontología de los estados de cosas o la filosofía lingüística de la figuración lógica de un mundo constituido por estados de cosas. Al contrario, la supone para su concepción de un uso lingüístico con sentido, e intentó aclarar estos supuestos ontológico-trascendentales dentro de una concepción del "atomismo lógico" que va mucho más allá de B. Russell, una 
concepción, cuya precisabilidad queda ahí como algo único en la historia de los sistemas filosóficos. ${ }^{2 \overline{5}}$

Si nos es permitido considerar esta ontología del "atomismo lógico" como una versión - por cierto muy moderna y refinada- de la "ontología del ser-ante-los-ojos de lo ante-los-ojos", llamada así por Heidegger, entonces llegamos a la siguiente comprobación en el paralelo de la crítica a la metafísica entre Heidegger y Wittgenstein: mientras en $\mathrm{El}$ ser y el tiempo Heidegger no sólo combate el general olvido del ser mediante el punto de vista de la "diferencia óntico-ontológica", sino pone en cuestión especialmente la oculta prerrogativa de la ontología del ser-ante-los-ojos de lo ante-los-ojos, la crítica metafísica del Wittgenstein primero resulta exclusivamente de la agudización paradójica de la diferencia óntico-ontológica en el ámbito de validez de la ontología del ser-ante-los-ojos de lo ante-los-ojos: mediante la distinción de lo que se puede decir (sc. "lo que es el caso"), y de lo que en la afirmación solamente se "muestra" (sc. "la forma lógica" del mundo). Wittgenstein señala aquí - para hablar con Heidegger- que la lógica de nuestro lenguaje solamente nos permite afirmaciones con sentido sobre estados de hecho "ónticos" ("intramundanos"), pero no sobre el "ser" o la "comprensión del ser", que nos entrega a priori el ser-ante-los-ojos de estos estados de hecho (de los "estados" y "situaciones" de cosas). La "entrega previa" de todo ente conforme a la ontología del ser-ante-los-ojos, sin embargo, no es puesta en cuestión por Wittgenstein. Es más, él tiene la firme convicción de que la apariencia metafórica de las afirmaciones ontológico-trascendentales se apoya precisamente en que nuestro lenguaje, en cuanto lenguaje descriptivo, no se puede ni debe desprender del esquematismo de la representación gráfica de estados de cosas intramundanas. (Determinante para esta absolutización de la ontología del ser-ante-los-ojos en el Wittgenstein primero era, sin lugar a duda, la concepción del lenguaje ideal, como pareció hacerse visible en la lógica matemática de Frege y Russell en cuanto forma de precisión "del" lenguaje humano.)

También para Heidegger vale el presupuesto de que el "olvido del ser" - tanto como no consideración de la diferencia óntico-ontológica, como especialmente en cuanto caída en la comprensión del ser ontológico-substancial de la ontología del ser-ante-los-ojos - está esencialmente condicionado por el "preconcebir" lingüístico de la metafísica tradicional (que en la logística moderna y en su especulación ontológica funge en cierta medida como último "metalenguaje"). Pero en $E l$ ser y el íiempo Heidegger intentó (precisamente con ayuda del lenguaje cotidiano no-teórico del "público estar interpretado" del mundo en el "cotidiano estar-en-el mundo"), dejar pasar, por decirlo así,

25 Esto lo ha mostrado especialmente la reconstrucción de E. Stenius (loc. cit.). Cfr. al respecto ahora W. Stegmüller cn: Philosophische Rundschau, 13. Jahrgang (1965), págs. $116-198$. 
el lenguaje de la onto-lógica tradicional y poner a discusión una comprensión del ser más originaria, que en el esquematismo categorial de la ontología del ser-ante-los-ojos tiene sólo su modus deficiente.

Y justo esta relativización de la ontología del ser-ante-los-ojos fue realizada igualmente por Wittgenstein -a su manera- en la segunda época de su filosofar, que comenzó poco después de su traslado a Inglaterra en el año de 1929. Ciertamente no le va en juego a él -como a Heidegger en 1927 en El ser y el tiempo- la constitución de una ontología-fundamental; más bien quisiera él ahora - conforme a su sostenida sospecha de falta de sentido contra toda filosofía teórica - "mostrarle" definitivamente a la mosca "la salida de la botella" ${ }^{26}$ e "imponer reposo" ("como a una enfermedad") a los problemas ontológico-metafísicos mediante crítica terapéutica del lenguaje. ${ }^{27}$ Sin embargo, los ejemplares análisis-"de juego del lenguaje" que se encuentran en los apuntes de las lecciones de 1933-1935 (los llamados "Blue and brown Books") y en las Investigaciones filosóficas, publicadas póstumamente en 1953, contienen - por lo menos en forma implícita- una teoría no sólo de la constitución del objeto, sino primariamente de la preobjetiva "entrega mundana" desde la comprensión previa del ser del lenguaje cotidiano entretejido con la praxis vital.

Si se reflexiona, pues, que también para Heidegger la interpretación "ontológica" de su "hermenéutica del cotidiano ser-en-el-mundo" no debía sostener la última palabra, se tiene toda la base para comparar en primer término, independientemente de la pregunta por la última finalidad de Heidegger y Wittgenstein, la hermenéutica del cotidiano ser-en-el-mundo y el análisis de los juegos de lenguaje cotidianos.

En atención al método de Heidegger primariamente fenomenológico-ontológico y al método de Wittgenstein primariamente analítico-lingüístico, sin duda será útil en semejante tentativa establecer una relación entre los modelos categoriales básicos de la ontología occidental por una parte, y por otra, de la filosofía del lenguaje. Una relación semejante - en cierto modo lo que correlaciona la terminología de Heidegger y Wittgenstein- se impone francamente, si se trata de leer los $\$ \S 1-38$ de las Investigaciones filosóficas de Wittgenstein, por decirlo así con los ojos de Heidegger: se encuentra aquí, dicho grosso modo, una discusión del modelo de pensar dominante en la Iógica del lenguaje desde Aristóteles, según el cual las palabras del lenguaje tienen su "significación" porque "designan algo", y esto quiere decir -siguiendo hasta su origen el esquema representativo subyacente aquí-: porque las palabras son "nombres" para "cosas ante los ojos" u "objetos". ${ }^{28}$

26 Philosophische Untersuchungen, I, § gog. [Trad. esp. de Alejandro Rossi, que se publicará en ig67 en la Serie Filosofia Contemporánea, del Centro de Estudios Filosóficos.] 27 lbidem, § 133, o también 255 .

$28 \mathrm{Cfr}$. para lo siguiente E. K. Specht: Die sprachphilosophischen und ontologischen Grundlagen im Spätwerk Ludwig Wittgensteins. Colonia, 1963. 
De este modo resulta el punto de vista heurístico de comparar la discusión del modelo designativo de la filosofía tradicional del lenguaje de Wittgenstein con la discusión de la ontología del "ser-ante-los-ojos" de Heidegger (o de su filiación moderna: la ontología y filosofía trascendental de la "objetividad").

Dentro de la historia de la filosofía va a terminar esto en una destrucción paralela de la lógica tradicional del lenguaje y de la ontología, que en la Escolástica medieval efectivamente apenas pueden ser separadas una de otra: expliquemos esto brevemente por medio de algunas indicaciones his. tóricas.

A la lógica tradicional del lenguaje le era claro, y por cierto desde Aristóteles, que las palabras, en tanto tienen una significación universal, no son nombres propios, y que, también como designaciones universales, no todas están como nomina (en el sentido de la gramática) en lugar de "substancias", sino también de "cualidades", "relaciones" y otras entidades, que según Aristóteles solamente de modo análogo pueden concebirse como cosas o pragmata. Por sobre esto, a propósito de las determinaciones llamadas después trascendentales, como "ser" y "unidad", y asimismo de las "palabras de enlace" o "partículas lógicas" en general, Aristóteles puso en entredicho que designaran algo real. Mas precisamente estas distinciones -fundamentales para la filosofía del lenguaje y la ontología occidentales- muestran que el problema de la "significación" de las palabras sólo pudo pensarse de acuerdo con el esquema representativo de la "designación", y esto quiere decir, propiamente de la "denominación" de una cosa ante los ojos mediante un nombre. Si esta representación no era aplicable, se caía en el desconcierto, como lo atestigua la clasificación de las partículas lógicas como synkategoremata o la problemática de la "analogía" de los kategoremata en la tesis escolástica: tot praedicamenta tot res. Es más, todavía la protesta nominalista contra la hipostación cósica de todos los kategoremata muestra que toda la disputa de los universales tiene su presupuesto filosófico-lingüístico en la concepción del "significado de las palabras" como "designación de algo" - así sea este "algo" una res en sentido propio o analógico, o una cosa concreto-individual o un universale ante res o un universale in rebus, o solamente un ens rationale, un conceptus. Por esto, según Wittgenstein, los representantes de ambos partidos en la disputa de los universales eran propiamente "nominalistas", en el sentido de un modelo de representación filosófico-lingüístico; pero sobre todo aqueilos refómadores matemáticos de la lógica del lenguaje, como Frege, Russell y el joven Wittgenstein, eran aun ellos "nominalistas", que en la víspera y al comienzo del siglo $\mathrm{xx}$ quisieron poner en una clara fórmula el problema del significado según la alternativa: o tiene significado una palabra, y entonces tiene el carácter de un nombre que denomina a un objeto en el más amplio sentido y puede ser instituido 
como valor para una variable en el cálculo lingüístico-objetivo de la logística; o -y esta posibilidad fue pensada hasta su último límite primeramente por el joven Wittgenstein en forma paradójica- la palabra no tiene en absoluto ningún significado, no está en vez de algo, sino que sólo "señala" —n cuanto "constante lógica" - la "forma lógica" del lenguaje y del mundo.

La tradición entera de la lógica del lenguaje occidental, poco antes señalada, que hasta cierto punto culmina en el Tractatus logico-philosophicus del Wittgenstein primero, la desea el Wittgestein posterior caracterizar y trascender, al escribir en las Investigaciones filosóficas ( $\$ 383$ ):

“. . los nominalistas cometen el error de explicar todas las palabras como nombres, esto es, no describen realmente su empleo, sino por decirlo así dan sólo una indicación formularia de una descripción tal".

Hasta para la formación radical del nominalismo filosófico-lingüísticoontológico, que conduce al "atomismo lógico" y a su distinción entre variables-nombres y forma lógica del lenguaje, encuentra Wittgenstein ahora una temprana comprobación histórica en el Teetetes, donde Sócrates expone la siguiente hipótesis:

"Si no me engaño, he escuchado de algunos que para los elementos primitivos - para expresarme asi-, de los que estamos compuestos nosotros y todo lo restante, no hay ninguna explicación; pues todo lo que es en sí y por sí sólo se puede designar con nombres; otra determinación no es posible; ni la de que es, ni la de que no es... Mas por esto es imposible hablar en forma explicativa de un elemento cualquiera primitivo; pues para éste no existe sino la pura denominación; sólo tiene, en efecto, su nombre. Mas, sobre cómo lo que se compone de estos elementos primitivos es ello mismo una estructura constituida, a ese respecto sus denominaciones han venido a ser en esta constitución discurso explicativo; pues su esencia es la constitución de nombres." 20

No puede haber ninguna duda de que también Heidegger considera toda la lógica tradicional del lenguaje como correlato de la ontología por destruir de lo ante los ojos en su puro ser ante los ojos, y de que en la cuestión de la disputa de los universales no sólo les reprocharía a los habitualmente llamados nominalistas y a sus continuadores modernos, los positivistas, olvido del ser en el sentido de un estar abandonado a lo ante los ojos intramundano, sino precisamente también a los llamados realistas de los universales, quienes creen tener que pensar el ser del ente como un ente de una especie particular.

Por cierto que en este paralelo llaman la atención dos cosas:

I) Por lo menos el Heidegger primero, en contraste con Wittgenstein, hace que la lógica del lenguaje (aristotélico-russelliana) se funde en la onto- 
logía de lo ante los ojos, más bien que, al revés, la ontología de lo ante los ojos se funde en el -especial- “juego lingüístico de la imposición de nombres" o de la "explicación indicadora de nombres". Se podría estar tentado a decidir entre estos resultados divergentes de un enfoque más fenomenológico y de otro más analítico-lingüístico, en el sentido de que para el nacimiento del lenguaje filosófico (como ya antes para el de la filosofía inmanente al lenguaje) es más plausible el abandono de la comprensión del ser al carácter de cosa, que se despliega, del mundo experimentable sensiblemente, mientras después el preconcebir lingüístico de la ontología substancial, que se refleja en la lógica nominalista del lenguaje, fija desde éste la concepción mundana teórico-objetiva de la ciencia.

2) El segundo punto que llama la atención y ofrece dificultades en nuestro fundamental cotejo entre Heidegger y Wittgenstein sobre el problema de una destrucción del nominalismo lógico-ontológico, es la circunstancia de que el Wittgenstein posterior parece dirigir su destrucción en primera línea contra aquellos "nominalistas" filosófico-lingüísticos, que -como platónicos- también entienden las funciones del lenguaje, no demostrables mediante un "juego lingüístico de explicación indicadora", como funciones designativas, y desde ahí son llevados a la hipostación de tantas entidades cuantas palabras existen. Esta tendencia de Wittgenstein se muestra especialmente en su crítica del supuesto socrático-platónico de una "esencia" permanente y unitaria como "substancia" de los significados de las palabras en las Investigaciones filosóficas, así como en su crítica radical de toda fundamentación platónico-infinitista del concepto de número y hasta del concepto, supuesto por los "intuicionistas", de una "regla" de construcción en las "Observaciones a los fundamentos de la matemática". ${ }^{30}$ Frente a esto, en el campo del positivismo moderno se ha recibido siempre la ontología fundamental de Heidegger como un realismo extremo de los universales, especialmente el hablar del "ser" y de la "nada". La impresión de que aquí se ofrece una antítesis en relación a la disputa de los universales, sorprende efectivamente al que está fuera, sobre todo en la comparación del estilo de lenguaje heideggeriano con el de las Investigaciones filosóficas: pues, según parece, Heidegger intenta, a menudo con una sola metáfora, hipostasiante ya casi en forma mitológica, poner a discusión lo que Wittgenstein más bien indica que afirma de un modo teóricamente explícito mediante una cantidad de ejemplos en su "Álbum" filosófico." ${ }^{31}$ Así por ejemplo, el hablar Heidegger del lenguaje como la "casa ciel ser" y la "morada del ser humano" 32 contiene en cierta forma un equivalente resumido de lo que el lector apren-

so Cfr. W. Stegmüller en Philosophische Rundschau, 13. Jahrgang (1965), págs. 138-152.

31 Cfr. el "Prefacio" de las Philosophische Untersuchungen.

32 Platons Lehre von der Wahrheit, mit einem Brief über den Humanismus, Berna, 1947, pág. 115. 
dió después de la lectura de las Investigaciones filosóficas sobre el nexo entre el lenguaje y la "forma de vida" humana, y también entre la "gramática profunda" y la "estructura esencial" del mundo, válida a priori.

Sin querer restar importancia a la distinción, indicada poco antes, en la dicción y con ello también en el método de Heidegger y Wittgenstein, con todo me parece no estar tan profundamente enraizada, como hace suponer el recíproco aislamiento y rechazo de las dos escuelas filosóficas procedentes de ambos pensadores. Mas bien me parece que sólo resulta comprensible, si se ve en ella la doble expresión de una posición, que precisamente es común a Heidegger y Wittgenstein: el indicado distanciamiento crítico del modelo de pensar nominalista -en un sentido más profundo- o de la ontología respectiva. Con base en este distanciamiento ni Wittgenstein puede "reducir" la precomprensión mundana implicada en la gramática profunda del lenguaje a lo designable en sentido del positivismo, ni Heidegger puede entender el ser del ente como un ente designable. Más bien ambos pensadores procuran poner a discusión la multiplicidad y profundidad de la comprensión del ser, no objetiva, pero sí supuesta ya para la constitución objetiva, de tal manera que el "contraataque" contra el lenguaje de la metafisica permanece siempre efectivo. El Wittgenstein posterior trata de alcanzar esto no estableciendo en lo posible absolutamente ninguna tesis teórico-objetiva a la manera de la ciencia; Heidegger lo hace, en primer lugar, intentando trazar la nueva dimensión en un sistema conceptual inusitado, a menudo violentamente provocador $y$, después, sobre todo tomando prestadas a la etimología o al lenguaje poético imágenes y metáforas, que son tan extrañas, que precisamente por ello anulan la apariencia metafórica de la ontología de la objetividad, ya dispuesta en nuestro lenguaje.

El Heidegger posterior ha expresado varias veces muy claramente la dificultad fundamental que le resulta del contraataque al lenguaje de la metafísica. En tal sentido se dice en la introducción a la 5 " edición de "¿Qué es metafísica?":

"El intento de pasar de la representación del ente en cuanto tal al pensamiento de la verdad del ser, debe, partiendo de aquella representación, representar aún en cierta forma también la verdad del ser, de manera que esta representación permanezca necesariamente de otra indole $y$, en definitiva, en cuanto representación, inadecuada a lo por pensar."

Que en esta gravosa situación de apuro, en que el representar debe ser relegado a sus límites por un representar de otra índole, el lenguaje del representar participa esencialmente, lo descubre el siguiente pasaje de Identidad $y$ diferencia: ${ }^{33}$

"Lo difícil se halla en el lenguaje. Nuestras lenguas occidentales son, cada una de diversa manera, lenguas del pensamiento metafísico. Si la esen-

s3 M. Heidegger: Identität und Differenz, Pfullingen, 1957 , pág. 72. 
cia de las lenguas occidentales fue en sí acuñada sólo metafísicamente, y según ello de manera definitiva por la onto-teo-lógica, o si estas lenguas ofrecen otras posibilidades del decir, y ello significa, a la vez, del no-decir dicente, tal problema tiene que permanecer abierto."

Con esto podrian compararse los siguientes pasajes de las Investigaciones filosóficas de Wittgenstein:

"Donde nuestro lenguaje nos hace suponer un cuerpo, y no hay cuerpo alguno, ahí, quisiéramos decir, hay un espiritu." ( $\left(3^{6}\right)$ Así "¿se llega al problema fílosófico de los procesos y estados anímicos y del behaviorismo? - el primer paso es completamente accidental. Hablamos de procesos y estados, y ¡dejamos su naturaleza indeterminada! Quizá alguna vez sabremos más sobre ellos - opinamos nosotros. Mas precisamente por esto nos hemos atado a una determinada manera de considerar. Pues nosotros tenemos un determinado concepto de lo que significa: aprender a conocer más de cerca un proceso. El paso decisivo en el arte de la prestidigitación ha sido dado, y precisamente él nos pareció inocente". Al adentrarnos más a fondo en el problema, nos volvemos críticos: "Y entonces se desbarata la comparación que nos debería hacer comprensibles nuestros pensamientos." Y luego caemos -conviene a saber, dentro de la filosofía naturalista-behaviorista- en la aporía opuesta:

"En consecuencia, tenemos que negar el proceso aún no entendido en el medio aún no investigado. $Y$ así nos parece haber negado, pues, los procesos espirituales. Y sin embargo, no queremos negarlos." ( $\left.\$ 3^{08}\right)$

Aquí caracteriza Wittgenstein acertadamente el dilema, que en su propio método corresponde a la dificultad de Heidegger en el pensamiento del ser: mientras Heidegger cae siempre de nuevo en el peligro de hacerse, sin quererlo, mediante sus ensayos especulativos de una filosofía que trasciende la metafísica, no obstante, una representación objetiva de lo que no puede ser representado como una cosa, el Wittgenstein antiespeculativo cae en el peligro, a causa de su negación de los fenómenos espirituales hipostasiados objetivamente, de ser confundido con los positivistas, que niegan absolutamente estos fenómenos, o los tratan de reducir a fenómenos tales, que se puedan describir en el "lenguaje de cosas" de la física.

El ejemplo de la representación cósica de lo espiritual, que Wittgenstein analiza, recuerda por lo demás la crítica a Descartes de Heidegger en El ser y el tiempo, cuyos puntos crítico-lingüísticos precisamente desembocan en que Descartes, con ia preguntá: “Qué es el indubitable ego cogito?”, da aquel paso, en apariencia inocente, que lo ata a una determinada manera de considerar (substancial-ontológica), mediante la apariencia metafórica de la pregunta por el "qué". (Si Descartes responde a esa pregunta: El ego cogito es una res sive substantia cogitans, con esto causa él a fin de cuentas aquellos problemas aparentes adivinados así por Heidegger como por Witt- 
genstein, como la existencia de un mundo exterior o la coincidencia de este mundo exterior con el sujeto que existe aisladamente de aquél en la acción intencional o en el conocimiento. ${ }^{34}$

Después de que hemos comprobado así la más profunda comunidad entre Hẹidegger y el Wittgenstein posterior en el intento de una superación crítico-lingüística de la onto-lógica, vamos a investigar en lo que sigue, hasta dónde llega el paralelo en la relativización de esta onto-lógica con base en una fenomenología positiva del cotidiano ser-en-el-mundo o de los juegos lingüísticos de todos los días.

Según Wittgenstein, la representación tradicional de una "denominación" de objetos, o de la explicación de significados de palabras mediante un "explicar indicador" de la función denominativa de las palabras, no es tal vez enteramente errónea. Más bien ha sido descifrada en un juego lingüístico que efectivamente ocurre en la praxis de la vida, por ejemplo, en ciertos métodos de la enseñanza del lenguaje.

Entonces fácilmente parece aquí como si el hombre ya conociera siempre un mundo de objetos estructuralmente articulado y el aprendizaje ordinario del lenguaje consistiera esencialmente en la atribución correcta de nombres a objetos conocidos. Más o menos así describió de hecho San Agustín en las Confessiones el propio aprendizaje del lenguaje:

"Cuando los adultos nombraban un objeto cualquiera y al efecto se volvían hacia él, yo percibia eso y comprendía que el objeto era designado mediante los sonidos que ellos pronunciaban, puesto que querían referirse a él." (I. F. [Investigaciones filosóficas], § 1).

Esta representación del aprendizaje originario del lenguaje, empero, pasa por alto, según Wittgenstein, el que un niño, que por primera vez aprende el lenguaje, no puede aún entender en manera alguna explicaciones indicadoras, puesto que no dispone todavía ni de una articulación estructural del mundo, que le diga a qué se alude en cada caso mediante una indicación (si, por ejemplo, color o forma o especie o número), ni conoce aún la función en el lenguaje de la palabra por aclarar, o su aplicación. Una explicación indicadora de nombres la entiende, según Wittgenstein, sólo aquel "que sabe ya emprender algo con ella" (I. F., \$ 31): "Se tiene ya que saber o ser capaz de algo, a fin de poder preguntar por la denominación..." (I. F., § 3o). Si yo, por ejemplo, señalo un objeto y explico: "Éste es el rey", dicha explicación puede tener sentido tal vez como denominación de una pieza de ajedrez. Mas esto supone, como explica Wittgenstein, que "el que aprende ya sabe qué es una pieza de juego". Que "por tanto, quizá ha jugado ya otros juegos, o que ha presenciado 'con inteligencia' el juego de otros - y cosas semejantes". (I. F., § 31).

34 Cfr. con esto también la crítica a Descartes sostenida según el espíritu de Wittgenstein en The Concept of Mind. 
Según esta explicación de Wittgenstein, puede uno fácilmente represen. tarse lo que supone una plena comprensión de la explicación: "éste es el rey", si se alude al representante efectivo de una monarquía. Por tanto, al querer San Agustín reducir, desde el horizonte de comprensión de la filosofía nominalista del lenguaje, el aprendizaje del lenguaje a la explicación indicadora de nombres, entonces, según Wittgenstein, describe él "el aprender del lenguaje humano, como si el niño llegara a un pais extraño y no entendiera el lenguaje del país; es decir: como si tuviera ya un lenguaje, pero no ése. $O$ también: como si el niño pudiera ya pensar, pero todavía no hablar..." (I. F., § 32).

El sentido positivo, sólo señalado por Wittgenstein, de estas indicaciones de los inadvertidos supuestos del juego lingüístico de la denominación, o de la explicación indicadora de nombres, sólo se puede sacar del contexto de su característica de los "juegos de lenguaje" como unidades de uso lingǘstico, praxis de conducta y descubrimiento de situación; en suma: como "formas de vida". Ese sentido, dicho brevemente, está en la superación de aquella idea, enraizada profundamente, de la teoría tradicional del conocimiento y de la filosofía del lenguaje, según la cual en primer término conocemos un mundo de objetos -en lo posible cada uno por sí- y posteriormente hacemos corresponder signos a estos objetos, para poder retenerlos en la memoria y comunicarlos a otros. Como verdadero núcleo de esta representación modelo se descubre para Wittgenstein la función del juego lingüistico de la denominación o de la explicación indicadora de nombres. Este juego lingǘstico, sin embargo, es un fenómeno secundario "múltiplemente" fundado, que sólo representa algo así como un "modus deficiente" de aquellos juegos lingüísticos en que los niños, juntamente con el aprendizaje de su lengua materna, asimilan también una determinada forma de vida y una determinada comprensión del mundo, estructuralmente articulada, como situación de la praxis vital.

Al aplicar nosotros poco antes el punto de vista del "modus deficiente" o del estar fundado a la no independencia, expuesta por Wittgenstein, del juego lingüístico de la denominación, hemos ya señalado las correspondencias con la hermenéutica del ser-en-el-mundo de Heidegger. Éstas se pueden comprobar, tanto con respecto a la "articulación de significatividad" del llamado por Heidegger mundo-"útil", como del "ser-juntamente" con los otros, llamado así por Heidegger; especialmente se refieren a ellas las maneras regulares del ser-juntamente en el modus del "se" y el "público estar interpretado" del mundo, determinado desde aqui.

Con respecto a la articulación de significatividad del mundo (como del "en dónde del comprender, que se refiere"), la más profunda correspondencia entre Wittgenstein y Heidegger se halla en el reconocimiento de que todas las "explicaciones" científicas, en cuanto enlaces lógicos de los llama- 
dos "datos", presuponen ya un "comprender" originario de "algo en cuanto algo", que en cada caso puede entregar muy diversos "datos" según el juego lingüístico entretejido con la forma de vida. En Heidegger resulta esto de la "igual originariedad" de los existenciarios "hallarse", "comprender" y "habla", habiéndose concretizado esta última, de acuerdo con el "estado de yecto" del ser-ahí sobre una situación, siempre en la forma de un "lenguaje" determinado histórico-mundial. ${ }^{35}$ En Wittgenstein justamente este supuesto de una precomprensión del mundo articulada lingüísticamente es explicado con ejemplos que deben demostrar el sinsentido de la pregunta por "la" estructura ontológica del "mundo en general". Por ejemplo en la siguiente observación:

"Pero, ¿cuáles son los elementos simples, de los que se compone la realidad? - ¿Qué son los elementos simples de un sillón? - ¿Las piezas de madera, de las que está ensamblado? ¿O las moléculas, o los átomos? 'Simple' quiere decir: no compuesto. Y - ahí está lo importante: ¿'compuesto' en qué sentido? No tiene ningún sentido hablar de los 'elementos simples del sillón absolutamente" (I. F., § 47).

Con Heidegger se podría explicar: lo importante es el "por mor de que" de la "cura" respectiva del ser-en-el-mundo: desde él nos ha sido proyectado siempre a nosotros hombres un horizonte-de-"conformidad", que -como simbólico "contexto de referencia" - dirige nuestra búsqueda de los elementos del sillón y se hace conforme con partes muy determinadas. Este análisis estructural de la hermenéutica existencial podría a su vez ejemplificarse en sentido de Wittgenstein de la siguiente manera: si la pregunta por los elementos del sillón es planteada desde el juego de lenguaje profesional de los transportadores de muebles, los elementos, con los que nos hacemos conformes, serán diversos que si se trata de la pregunta de químicos o físicos atómicos.

Al tomar en consideración nosotros, junto con Wittgenstein, el "estar entretejido" del juego lingüístico, que guía de manera "previa-concomitante" el descubrimiento del mundo, con una forma social de vida, acertamos a la profunda convergencia de sus puntos de vista con los de Heidegger en el problema de la tradicionalmente llamada "intersubjetividad".

A Heidegger se le pasa aquí en cierto modo el principio solipsista de la "teoría del conocimiento" tradicional a través del concepto del "ser uno con otro". Mientras la filosofía que parte del sujeto del conocimiento cree tener que constituir como objeto "de mi conciencia" el ser de los otros exactamente como el ser de las cosas del mundo exterior, Heidegger da vigencia al punto de vista fenomenológico-hermenéutico de que el "yo", el "tú" y los "otros", como datos mencionables con sentido, se constituyen "origina- 
riamente igual" desde el "ser uno con otro" de nuestro ser-en-el-mundo; y por encima de esto reconoce que en el "público estar interpretado" del mundo la precomprensión - acuñada tradicionalmente en el lenguaje- se anticipa siempre en el modus del "se" al poder-opinar del individuo y lo guía "en primer lugar" y "la mayoría de las veces" en la conducta media de todos los días.

Esta superación del solipsismo metódico la confirma el Wittgenstein posterior en forma notable mediante su discusión aporética de la pregunta por la posibilidad de un lenguaje privado.

Lo aparentemente constrictivo de la idea de que tiene que poder darse un lenguaje privado descansa, según Wittgenstein, al igual que el solipsismo metódico de la teoría moderna del conocimiento, en el supuesto de un sujeto que existe aisladamente y que designa con nombres sus sensaciones - por ejemplo, los dolores- como objetos accesibles solamente a él. Wittgenstein ilustra este supuesto por medio de la siguiente comparación:

"Supongamos que cada quien tuviera una cajita y que allí estuviera algo que nosotros llamamos 'escarabajo'. Ninguno puede ver en la cajita del otro; y cada uno dice que, sólo por la visión de su escarabajo, sabe qué es un escarabajo. Pues ciertamente podría ser que cada uno tuviera en su cajita una cosa diversa. Es más, podría uno imaginarse que tal cosa se cambia constantemente." Hasta aquí Wittgenstein aclara la reflexión que parece conducir a la hipótesis de un lenguaje privado posible, es más, necesario. Mas luego prosigue: “Ahora bien, ¿y si la palabra 'escarabajo' de esta gente tuviera, con todo, un uso? Entonces éste no sería el de la designación de una cosa. La cosa que hay en la cajita no pertenece en absoluto al juego del lenguaje; ni tan siquiera como un algo; ...mediante esa cosa de la cajita puede ser 'despejado'; eso se suprime, cualquier cosa que sea. Es decir: cuando se construye la gramática de la expresión de la sensación conforme al modelo de 'objeto y designación', entonces el objeto queda fuera de consideración como irrelevante." (I. F., § 293).

Con esto Wittgenstein no pretende decir que una sensación de dolor privada no es nada o pertenece tal vez sólo como sensación colectiva a un juego posible de lenguaje. Lo que él pretende decir es más bien esto: nuestras sensaciones privadas se hacen públicas en un medio intersubjetivo, porque nosotros hablamos de ellas (o por lo menos las expresamos). Sin enlace con este medio intersubjetivo, es decir, sin enlace con criterios externos como expresión, actitud dolorosa y palabras del lenguaje públicamente válidas unidas a ello, no podría el individuo experimentante ni siquiera identificar su sensación en cuanto tal y reconocerla de nuevo. ${ }^{36}$

$36 \mathrm{Cfr}$. Philosophische Untersuchungen, $\S 257$ : ¿Qué sucedería si los hombres no exteriorizaran sus dolores (que no se quejaran, que no contrajeran el rostro, etc.)? Entonces no se podría enseñar a un niño el uso de las palabras 'dolor de muelas'". 
Wittgenstein discute el mismo problema todavía en una forma diversa mediante la pregunta: “¿Qué significa seguir una regla?" (I. F., § 197 y ss.). "Lo que nosotros llamamos 'seguir una regla', ¿es algo que sólo un hombre, sólo una vez en la vida podría hacer?.." La respuesta de Wittgenstein reza: "Ni siquiera una única vez pudo haber sido hecha una comunicación, haber sido dada y comprendida una orden, etc. Seguir una regla, hacer una comunicación, dar una orden, jugar una partida de ajedrez, son costumbres (usos, instituciones). Entender una proposición significa entender un lenguaje. Entender un lenguaje significa dominar una técnica" (I. F., $\S 199)$.

Las consecuencias de estas tesis para la lógica de las ciencias sociales, que fueron sacadas hace muy poco, ${ }^{37}$ son parecidamente amplias, como aquellas que resultan de la indicación de Heidegger sobre la igual originariedad fenoménica entre "comprender" y "ser-con" para la fundamentación del entender hermenéutico en las ciencias del espíritu; se muestra, en efecto, que todo "comprender" de un comportamiento humano, en oposición al mero "explicar" de los procesos naturales, supone dos cosas: 1. Que la regla del comportamiento por entender deba ser controlable en el contexto de una forma social de vida, que a la vez sea un juego del lenguaje; 2. que el intérprete del comportamiento reglamentado tenga por principio que poder participar en este juego de lenguaje. Si no se cumple alguno de los dos supuestos, no puede excluirse una confusión del "entender" con una mera "explicación", que sólo desde fuera imponga una regla al comportamiento. ${ }^{38}$

La primera condición de un control social del comportamiento reglamentado por medio de otros puede ciertamente ser cumplida también por el intérprete mismo y, de ese modo, el cumplimiento de la primera y de la segunda condición coinciden, si la regla por entender es la de un diálogo. $\mathrm{Y}$ aquí tropezamos de hecho con aquel juego de lenguaje o con aquella forma social de vida, que fueron supuestos ya incluso para la validez de la lógica formal, es decir, para la comprensibilidad de aquellas reglas que implica todo comportamiento reglamentado. En otras palabras: de la penetración en la igual originariedad del "ser con", "comprender" y "habla" (Heidegger), o del "estar entretejido" de "juego lingüístico" y "forma social de vida" (Wittgenstein), resulta la posibilidad de una fundamentación de la lógica formal en el "diálogo" - una posibilidad que ha sido ya realizada por Paul Lorenzen en forma totalmente independiente.

${ }_{37}$ Cfr. R. Winch: The Idea of a Social Science and its Relation to Philosophy, Londres, $1958 ; 4^{3}$ ed., 1965 .

38 Así se funda de nuevo la antigua distinción metodológica de "explicar" y "entender" (o también de "ciencias naturales" y "ciencias del espíritu"). Cfr. a este respecto K. O. Apel: "Die Entfaltung der 'sprach-analytischen' Philosophie und das Problem der Geisteswissenschaften." En Philosophisches Jahrbuch, Munich, 1965, págs. 239-289 (Traducción inglesa en Foundations of Languaje, Suppl.-Series, 1967). 
EI paralelo entre la hermenéutica existencial de Heidegger y el análisis de los juegos de lenguaje como formas de vida de Wittgenstein se podría aún llevar mucho más lejos. En esa forma podrían compararse tal vez el implícito pragmatismo de la fenomenologia heideggeriana del cotidiano seren-el-mundo, del tener-que-hacer que se cura de y su descubrimiento de la "significatividad", con el "criterio de sentido" del juego de lenguaje que funciona en la praxis de la vida. En ambos casos la elaboración de complejos funcionales, práctico-vitales, sirve para poner en cuestión la ontología teórico-objetiva.

En este respecto es de mencionarse especialmente la amplia concordancia en la crítica del ideal matemático de exactitud.

Para Heidegger "los supuestos ontológicos del conocimiento historiográfico superan radicalmente la idea del rigor de las más exactas ciencias", "por ser el comprender en sentido existenciario el 'poder ser' del 'ser ahi' mismo" (El ser y el tiempo, págs. 177-8). ${ }^{39}$ * De manera semejante Wittgenstein relativiza también el ideal de la exactitud en dirección al objetivo que cada vez está en juego en una forma determinada de vida (I. F., § 88). Si en El ser y el tiempo Heidegger descubre la última medida oculta de todo entender y con ello también del apreciar y medir en el "por mor de" de la "cura" delser-ahí, entonces se dice en Wittgenstein: "El prejuicio de la pureza cristalina (se alude al ideal absoluto de exactitud de una metafísica de la lógica matemática) sólo puede ser eliminado si damos vuelta totalmente a nuestra consideración..., pero alrededor de nuestra propia necesidad como punto angular" (I. F., § 108).

El subrayar los aspectos pragmáticos en la filosofía de Heidegger y Wittgenstein, empero, se adapta también de modo excelente para caracterizar con alguna exactitud el punto de divergencia de ambos pensadores:

En el Wittgenstein posterior el pragmatismo, y por cierto un "pragmatismo del presente" pluralista-relativista-finitista, que supera con mucho en radicalidad a todas las especies del pragmatismo americano, es, según toda apariencia, el último fundamento metafísico-antimetafísico de su pensamiento. A la pregunta, por ejemplo, de por qué la filosofía de Wittgenstein, que en cuanto fenomenología descriptiva del empleo lingüístico "deja todo, como está",40 no hace valer tampoco los juegos de lenguaje especulativos de la metafísica en cuanto tales, no se da en las Investigaciones filosóficas ninguna otra respuesta que la sospecha de falta de sentido, dirigida ahora pragmáticamente, contra tales juegos de lenguaje, que ya no funcionan en el

39 En Wittgenstein se dice respectivamente: "La gramática de la palabra 'saber" está, de modo manifiesto, estrechamente emparentada con la gramática de las palabras 'poder', 'ser capaz'. Pero también estrechamente emparentada con la de la palabra 'entender'..." (Philosophische Untersuchungen, I, \& 150).

* [Trad. española del Dr. José Gaos.]

40 Philosophische Untersuchungen, I, § 124. 
contexto de la praxis vital, donde la máquina del lenguaje "marcha en vacio".41

Manifiestamente el criterio de sentido de la verificación práctica se halla también a la base de la peculiar caracterización del lenguaje cotidiano ("ordinary language") como la "patria" de todo uso verbal con sentido. En ello Wittgenstein tiene siempre ante los ojos una coordinación de formas sinópticas de la confirmación recíproca entre uso lingüístico y praxis vital. Es posible que estas formas sean diversas y estén sujetas al cambio: pero en todo caso se hallan al descubierto como unidades actualmente en función. La verificación práctica del "uso lingüístico" no puede, según Wittgenstein, consistir en que la comprensión de manifestaciones lingüísticas conduzca a una nueva fundación histórica de las formas de vida - en lo posible sobre la línea de una progresiva corrección del lenguaje y de la forma de vida, regulada por el telos del entendimiento universal. $\mathrm{Ni}$ el impulso interno de todo juego de lenguaje hacia la autorreflexión, el cual hace posible toda traducción e interpretación en las ciencias del espíritu, ni la continuidad, condicionada precisamente por ello, de un diálogo humano que enlace todos los juegos de lenguaje, vienen a discusión en Wittgenstein. Su análisis del lenguaje es ahistórico y -como se entiende casi de por sí- sin ningún fin ulterior especulativo.

Con el ahistórico pragmatismo del presente, propio de la concepción del juego de lenguaje del Wittgenstein posterior, está estrechamente relacionada además otra deficiencia observable en su filosofía lingüística: aun cuando Wittgenstein previene a los filósofos repetidamente contra una dieta unilateral de ejemplos, no se encuentran en su "Álbum" filosófico ningunos análisis del uso poético del lenguaje. Lo que en el fondo le impide esto es, en apariencia, precisamente su concepto instrumentalista del "uso del lenguaje". Wittgenstein compara el lenguaje no sin razón con una "caja de herramientas" y pone en juego la ilimitada variedad de las funciones instrumentales en contra de la "función designativa", monopolizada desde Aristó. teles por la filosofía del lenguaje. Con ello indudablemente hizo posible una fructífera ampliación del pensamiento filosófico-lingüístico: una ampliación, por lo demás, que podría estar tan conforme con la relación instrumental-operativa del hombre moderno respecto del mundo y del lenguaje, como el modelo aristotélico de la designación lo estaba con la relación teórico-contemplativa de los griegos respecto de un cosmos, que pasa como determinado en su esencia previamente a toda praxis lingüística de los hombres y, según esto, sólo ha de designarse y conocerse.

Sin embargo, esta interpretación instrumentalista de la esencia del lenguaje podría iluminar solamente una tendencia de primer plano en la re-

41 Ibidem, § 132. 
lación del hombre moderno con el lenguaje. Según Wittgenstein, ella permite calcular debidamente la multiplicidad de los modos de empleo del lenguaje en atención a una multiplicidad de los fines que deben suponerse o de las necesidades de la praxis humana. Por el contrario, no permite "percibir" todas las formas del - sit venia verbo- "uso del lenguaje" en general, y mucho menos apreciarlas, en las que el sentido de las palabras ha de juzgarse no desde su función instrumental en el contexto de un propósito ya fijo de juego de lenguaje, sino desde la superior necesidad del hombre de lograr ante todo un horizonte de sentido para los verdaderos fines y necesidades de la praxis. Esta "meta-necesidad" podría estar en una relación complementaria con una instrumentalización, siempre progresiva, del lenguaje en la política, en la técnica, en la economía y en la ciencia, y crecer en una relación complementaria; y ella podría tal vez producir en el arte, en la religión y en la filosofía especulativa juegos de lenguaje, en los que no tanto la regla convencional del empleo fija el sentido de las palabras y proposiciones como "útiles de trabajo", sino más bien al revés, la concentración de sentido en palabras y proposiciones colabora en la construcción de un juego de lenguaje $y$, con ello, de una nueva forma de vida. Aquí habrian de poder tomarse en cuenta las llamadas figuras de lenguaje y metáforas en el más amplio sentido, todos los "medios" de-los poetas para enajenamiento de la comprensión de sentido convencional y estancada en patterns gramaticales, todos los intentos de los filósofos - cargados con el peligro de crear problemas aparentes - para decir lo que, según Wittgenstein, no puede decirse.

Se habrá observado que en la crítica de la filosofía del lenguaje de Wittgenstein, concebida instrumentalista y ahistóricamente, he hecho uso de puntos de vista y "preconceptos" lingüisticos, que se pueden lograr quizá sólo a partir de Heidegger, dicho más exactamente: desde el Heidegger medio y posterior. Pues el análisis del mundo de trabajo y del mundo-"de útiles" en El ser y el tiempo, que tiene su punto de referencia supremo en el "por mor de qué" de la "cura"-del-ser-ahí, parece -como ya se indicócorresponder a una comprensión pragmatista del ser. $\mathrm{Y}$ hasta para una filosofía pragmatista del lenguaje, que entiende la función de los medios lingüisticos desde el "ser a la mano" del "útil" en el complejo de referencia de la comprensión situacional, se encuentra un punto de partida en El ser y el tiempo; por ejemplo en la frase:

'La señal es algo ónticamente 'a la mano', que en cuanto es tal determinado útil funciona a la par como algo que señala la estructura ontológica del 'ser a la mano', la totalidad de referencias y la mundanidad." ${ }_{22}$ Aquí, de modo parecido como en Wittgenstein, se ha hecho visible, en el marco de 
un horizonte pragmático, el carácter de referencia de signos, que fija a priori una precomprensión estructural del mundo; es más, la indicación de Heidegger de que la caracterización óntica de los signos consiste en hacer consciente la estructura ontológica de referencia del mundo situacional, podría ser entendida como una advertencia metodológica, de que se practica análisis del juego de lenguaje en lugar de fenomenología. Y de hecho Heidegger mismo ha ligado desde entonces más y más el método fenomenológico con el hilo conductor de una hermenéutica del lenguaje.

Sin embargo, al llamado "retorno" del análisis del "ser ahi" hacia la historia del ser, corresponde una nueva orientación ejemplar de la hermenéutica del lenguaje de Heidegger. No se llegó a una filosofía lingüística, que hubiera desarrollado la función-"útil" de las señales del lenguaje en el contexto del "tener-que-hacer que se cura" relacionado con el "por mor de qué de la cura". En lugar de esto, Heidegger mostró, por ejemplo en las interpretaciones de Hölderlin ${ }^{43}$ y en el artículo "El origen de la obra de arte",44 que el ser como "por mor de qué" de la "cura" no instituye ningún firme horizonte de fines antropológico-pragmático, sino que cada vez puede venir de nuevo a discusión en acontecimientos históricos de sentido. Tal “iluminación del mundo", que al mismo tiempo es una "gesta de la verdad", se realiza según Heidegger no en el lenguaje instrumentalista de cada día y del comercio técnico-científico, que bajo un preconcebir matemático pone a la disposición las cosas como útil a la mano o -en el caso límite- como "objetos" representables o "estados determinables", sino en el lenguaje de los poetas y pensadores, el cual hace a las cosas desplegarse de tal manera, que a la luz de su nueva significatividad el "ser ahí" del hombre se puede cambiar esencialmente.

De hecho me parece que en esta filosofía del lenguaje del Heidegger posterior orientada ejemplarmente hacia la obra de arte, puede entreverse una necesaria complementación y corrección del concepto técnico-científico del lenguaje de toda la filosofía analítica (y de la lingüística estructuralista por ella inspirada y de la estética del lenguaje). Al respecto podrían sin duda ser muy problemáticas en verdad las delimitaciones entre el lenguaje de la puesta a disposición técnico-científica, por una parte, y de la "institución verbal del ser", por otra; pues por cierto a veces la fórmula matemática puede contribuir a la "iluminación de la verdad del ente" y hasta al brillo de su hermosura, más bien que el esfuerzo profesional de "pen. sadores" y "artistas".

Esta dificultad, que podría estar fundada en el concepto heideggeriano de ciencia, me da motivo para una consideración crítica final, que aproxima todavía, una vez más, a Wittgenstein y Heidegger, y trata de restringir la

43 Sein und Zeit, $\$ 17$ ( $5^{\mathrm{a}}$ ed., Halle d. S., 1941, pág. 82).

14 Erläuterungen zu Hölderlins Dichtung, Frankfort d. M., 1944. 
validez de su destrucción de la metafísica tradicional a la luz de una posición, a mi modo de ver aún no quebrantada, del logos común a la filosofía y a la ciencia. El lema para nuestra crítica final lo ofrece el concepto poco antes expuesto de la "validez", es decir, de la obligatoriedad universal e intersubjetiva de una filosofía.

Que Wittgenstein haya respondido satisfactoriamente en su obra posterior la pregunta sobre la obligatoriedad de sus propias afirmaciones, que lo habian llevado a la paradoja en el Tractatus, nadie pretenderá afirmarlo. Él se sustrae a esta pregunta con la afirmación de que su filosofía no establece ningunas doctrinas universalmente válidas, sino que sólo tiene la función práctica de imponer reposo a la filosofía, yendo de caso en caso, mediante una aclaración de pensamientos crítico-lingüística. Esta labor "terapéutica", empero, que consiste sobre todo en el desenmascaramiento de la "apariencia metafórica" en los problemas planteados por la filosofía, no pue. de manifiestamente ejercerse como una medicina que opere en forma causal, sino que supone la convicción del paciente. En realidad, la crítica del lenguaje wittgensteiniana tiene también a su disposición argumentos convincentes, cuya validez de ninguna manera puede entenderse por el éxito pragmático de la terapia, sino que juntamente con éste debe atribuirse a la validez universal de una nueva penetración en la esencia del lenguaje. Wittgenstein, sin embargo - parecidamente a muchos pragmatistas y filósofos de la vida o de la existencia - no percibió ya la seriedad del problema de una autojustificación reflexiva de la filosofía. Parece haber sido para él algo satisfactorio reducir la validez de sus propias afirmaciones a juegos de lenguaje que funcionan fácticamente en el espacio y en el tiempo y cuyas reglas mismas - como los significados de las palabras- no poseen validez alguna supracomprensiva (trascendental), sino que deben ser finitas como las formas de vida correspondientes.

Se podría caracterizar la unilateralidad autodestructora de la crítica wittgensteiniana -para variar una palabra de Heidegger - como "olvido del logos". - ¿Eludió Heidegger el "olvido del logos", él que reconoció el "olvido del ser" de la metafísica occidental y especialmente de la ciencia moderna procedente de ella?

En nuestra confrontación de Heidegger con el Wittgenstein primero aludimos ya a que Heidegger descubrió ciertamente el logos hermenéutico del "comprender-se-en-la-situación" y la "reflexión" de la preontológica com. prensión del ser implicada en el lenguaje, pero no siguió hasta el fin el camino de la autogradación de la reflexión, camino ya abierto en la distinción del comprender "existencial" y "existenciario". ${ }^{45}$ En su filosofía posterior Heidegger abandonó luego definitivamente este camino de la filoso-

45 En Holzwege, Frankfort d. M., 1950, págs. 7-69. 
fía trascendental y fundó la "superación" de su pensamiento únicamente en la reflexión sobre el ser histórico, la cual marcha hacia adelante y a la vez recuerda.

Realmente me parece que el "logos hermenéutico" de las llamadas "ciencias del espíritu", y de una filosofía proporcionada por éstas, posee el fundamento de su fuerza explicativa en la tensión de la simultaneidad de un prepensamiento sobre las posibilidades del poder-ser humano y de una repetición de la historia del ser conservada y operante aún en la tradición. Con todo, me parece que la penetración reflexiva justo de ese fundamento del logos hermenéutico demuestra que la filosofía no recibe la legitimación de su pensar y decir únicamente del "prestar oído" a la oída "exhortación" del ser en el kairos histórico, sino también a la vez en la "autogradación de la reflexión", que debe renovarse constantemente, hasta el pensamiento del pensamiento en total validez universal intersubjetiva.

Esta última posición de la filosofía trascendental de procedencia hegeliana, que debe mantenerse firmemente, no puede por cierto sustituir o "anular" la reflexión substancial y efectiva de la conciencia perteneciente a la historia. Pero sí señala el punto en que la filosofía, y con ella la pretensión de validez universal de la ciencia, fue siempre fijada ya en la anticipación formal de todo fin posible en general de la historia del ser. Aquí toda discusión entre seres pensantes puede cimentar en cualquier tiempo el sentido racional de posibles argumentos y en esa forma dar validez a una contrainstancia crítica de la razón en vista de la abertura histórica de la verdad, que como dogmático-unilateral siempre tiene que implicar también la no verdad del ocultamiento de una posible verdad.

Un conocimietno filosófico, sin duda, que pretendiera establecerse solamente sobre el último grado de reflexión noológica, pagaría su falta de engagement con la no-obligatoriedad substancial de un vacío de contenido. Una filosofía, por otra parte, que funde su validez sólo en el engagement histórico, abandona al hombre al destino histórico y renuncia de nuevo a la emancipación del hombre respecto del destino, la cual habia sido ya alcanzada bajo el signo de la ilustración filosófica. A mi parecer todavía no poseemos una filosofía que haya conciliado en forma satisfactoria las profundas visiones de los siglos $\mathrm{xIx}$ y $\mathrm{xx}$ sobre la pertenencia al ser propia del hombre, de su lenguaje y de su pensamiento (desde la filosofía social de K. Marx hasta Wittgenstein y Heidegger) con la excéntrica pretensión de validez del universal logos intersubjetivo de la reflexión.

Karl OtTo APEL

(Traducción de Bernabé Navarro)

UNIVERSIDAD OF KIEL 